\title{
GO5.0: the joint NERC-Met Office NEMO global ocean model for use in coupled and forced applications
}

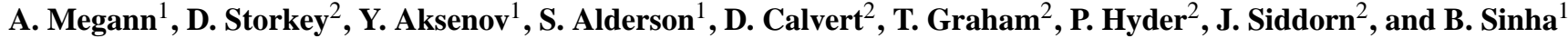 \\ ${ }^{1}$ Marine Systems Modelling, National Oceanography Centre, Southampton, SO14 3ZH, UK \\ ${ }^{2}$ Met Office, Hadley Centre, Exeter, Devon, EX13PB, UK
}

Correspondence to: A. Megann (apm@noc.ac.uk)

Received: 25 October 2013 - Published in Geosci. Model Dev. Discuss.: 26 November 2013

Revised: 6 March 2014 - Accepted: 7 April 2014 - Published: 6 June 2014

\begin{abstract}
We describe a new Global Ocean standard configuration (GO5.0) at eddy-permitting resolution, developed jointly between the National Oceanography Centre and the Met Office as part of the Joint Ocean Modelling Programme (JOMP), a working group of the UK's National Centre for Ocean Forecasting (NCOF) and part of the Joint Weather and Climate Research Programme (JWCRP). The configuration has been developed with the seamless approach to modelling in mind for ocean modelling across timescales and for a range of applications, from short-range ocean forecasting through seasonal forecasting to climate predictions as well as research use. The configuration has been coupled with sea ice (GSI5.0), atmosphere (GA5.0), and land-surface (GL5.0) configurations to form a standard coupled global model (GC1). The GO5.0 model will become the basis for the ocean model component of the Forecasting Ocean Assimilation Model, which provides forced short-range forecasting services. The GC1 or future releases of it will be used in coupled short-range ocean forecasting, seasonal forecasting, decadal prediction and for climate prediction as part of the UK Earth System Model.
\end{abstract}

A 30-year integration of GO5.0, run with CORE2 (Common Ocean-ice Reference Experiments) surface forcing from 1976 to 2005, is described, and the performance of the model in the final 10 years of the integration is evaluated against observations and against a comparable integration of an existing standard configuration, GO1. An additional set of 10year sensitivity studies, carried out to attribute changes in the model performance to individual changes in the model physics, is also analysed. GO5.0 is found to have substantially reduced subsurface drift above the depth of the thermocline relative to GO1, and also shows a significant improvement in the representation of the annual cycle of surface temperature and mixed layer depth.

\section{Introduction}

Coupled climate models developed at the UK Met Office have been at the forefront of international climate research and projections for the past 15 years. HadCM3 (Hadley Centre Coupled Model version 3; Gordon et al., 2000) was used in the Third and Fourth Assessment Reports (Houghton et al., 2001; Solomon et al., 2007) and is still widely used as a standard tool in climate research, while HadGEM1 (Hadley Centre Global Environmental Model version 1) (Johns et al., 2006), HadGEM2 (Collins et al., 2008) and HadGEM3 (Hewitt et al., 2011) have offered improvements in resolution, numerics and physics. All these models have an ocean on a horizontal grid of around $1^{\circ}$, although the HadGEM models have a refinement of the north-south grid scale close to the Equator down to $1 / 3^{\circ}$. In this paper we will refer to the model described by Hewitt et al. (2011) as HadGEM3, however newer versions currently in development, with a higher-resolution ocean, are also commonly referred to as HadGEM3.

Global ocean models are also used at the Met Office as part of seasonal and decadal forecasting systems (Arribas et al., 2011; Smith et al., 2007) and for ocean analysis and shortrange forecasting (Storkey et al., 2010). At the Met Office and elsewhere there is increasing interest in using a seamless modelling system for use at all timescales from short range forecasting to climate prediction (Brown et al., 2012).

Increased horizontal resolution in the ocean has been shown to have several benefits for modelling climate. In the North Atlantic the improved path of the Gulf Stream and North Atlantic Current (NAC) reduces the magnitude of a large cold bias off Grand Banks seen in many lowresolution climate models (e.g. Gnanadesikan et al., 2007; Danabasoglu et al., 2010). Reducing this bias has been shown 
to improve the frequency of blocking in a climate model (Scaife et al., 2011). In the tropical Pacific Ocean, eddy permitting resolution in HiGEM (High-resolution Global Environment Model) has been shown to help reduce the equatorial cold tongue bias (Shaffrey et al., 2009; Roberts et al., 2009) and the double intertropical convergence zone (ITCZ) bias, and also to more realistically simulate the westward extent of El Niño. Furthermore, teleconnections to the North Pacific Ocean associated with ENSO were also improved as a result of increased ocean resolution (Dawson et al., 2012). Eddy permitting models have an order of magnitude more eddy kinetic energy (EKE) than low-resolution models (Delworth, 2012) and the $1 / 4^{\circ}$ ORCA025 configuration has been shown to simulate $81 \%$ of observed sea level variability on interannual timescales (Penduff et al., 2010).

Ocean models run on horizontal grids fine enough to resolve eddies in the Southern Ocean show "eddy saturation", where increased vertical transport of momentum and meridional transport of heat away from the Antarctic Circumpolar Current (ACC) by the eddy field in response to increases in wind stress means that the isopycnal slopes and therefore the circumpolar transport is relatively insensitive to changes in the wind forcing (Tansley and Marshall, 2001; Hallberg and Gnanadesikan, 2006; Munday et al., 2013). This is not observed in lower-resolution models where the eddy transports are parameterised by diffusive schemes. A similar insensitivity of the global overturning circulation to the Southern Ocean wind forcing ("eddy compensation") is also seen in eddy-resolving models (Viebahn and Eden, 2010; Farneti et al., 2010) although some studies have suggested that eddy compensation can be achieved in lower-resolution models using a variable Gent-McWilliams coefficient and modified tapering scheme at the base of the mixed layer (Gent and Danabasoglu, 2011; Farneti and Gent, 2011).

Here we describe a new Global Ocean standard configuration (GO5.0) at eddy-permitting resolution, developed jointly between the National Oceanography Centre and the Met Office as part of the Joint Ocean Modelling Programme (JOMP), a working group of the UK's National Centre for Ocean Forecasting (NCOF) and part of the Joint Weather and Climate Research Programme (JWCRP). The configuration has been developed with the seamless approach to modelling in mind and is therefore intended to be used as the basis for ocean modelling across timescales and for a range of applications, from short-range ocean forecasting, through seasonal forecasting, to climate predictions as well as research use. The configuration has been developed for use throughout the UK academic and operational modelling communities. It has been coupled with the sea ice (GSI5.0), the atmosphere (GA5.0) and the land-surface (GL5.0) configurations to form a standard coupled global model (GC1). Additionally we take this opportunity to improve upon known deficiencies in the vertical mixing scheme and to take advantage of recent releases of NEMO and improvements in bathymetry data sets. The GO5.0 model will become the basis for the ocean model component of the Forecasting Ocean Assimilation Model (FOAM, Storkey et al., 2010), which presently provides forced short-range forecasting services to MyOcean (www.myocean.eu) and other users. The global coupled model will be used in coupled short-range ocean forecasting (as future versions of FOAM evolve into coupled systems), for seasonal forecasting as part of the GloSea4 (Global Seasonal forecasting system version 4) system (Arribas et al., 2011), for decadal prediction as part of the DePreSys (Decadal climate Prediction System; Smith et al., 2007) and for climate prediction as part of the UK Earth System Model (UKESM). The latter will be the UK's contribution to the upcoming IPCC (Intergovernmental Panel on Climate Change) Sixth Assessment Report and to the Coupled Model Intercomparison Project phase 6 (CMIP6).

We use the term "standard configuration" to denote all the items required to run the model, i.e. model code, input parameters and data sets, and compilation keys, and these are summarised in the Appendices A-E.

The main aim of this paper is to introduce the ocean model constituting GO5.0, and to evaluate its performance in oceanonly configuration, according to a set of first-order metrics. We will also compare the performance of GO5.0 with the previous global ocean configuration, which we denote GO1, and attribute the salient differences between the two model implementations to specific changes in model physics and parameter sets. Documentation of the attribution of changes in model behaviour to specific choices in a configuration will allow model developers using this or other models to make informed decisions and interpret model simulations with more clarity. Section 2 describes the ocean and ice models and the surface forcing fields. Section 3 summarises the main physics choices, and in Sect. 4 the experimental design is described. In Sect. 5 we present the results of the analysis: firstly the GO5.0 configuration is validated against observations; then GO5.0 is compared with the previous global model GO1; and the main improvements identified in GO5.0 are attributed to specific physics choices. Finally in Sect. 6 we summarise the results and discuss upgrades to the model currently under development.

\section{Model description}

GO5.0 is based on version 3.4 (v3.4) of NEMO (Nucleus for European Models of the Ocean) (Madec, 2008), and is closely related to the global DRAKKAR ORCA025 configuration (Barnier et al., 2006) sharing many of the same dynamics and physics choices. The horizontal grid, known as ORCA025, has $1 / 4^{\circ}$ resolution (1442 grid points $\times 1021$ grid points) at global scale decreasing poleward (an isotropic Mercator grid in the Southern Hemisphere, matched to a quasi-isotropic bipolar grid in the Northern Hemisphere with poles at $107^{\circ} \mathrm{W}$ and $73^{\circ} \mathrm{E}$ ). The effective resolution is approximately $27.75 \mathrm{~km}$ at the Equator, but increases with latitude to be, for example, $13.8 \mathrm{~km}$ at $60^{\circ} \mathrm{S}$ or $60^{\circ} \mathrm{N}$. The model 
has 75 vertical levels where the level thickness is a double tanh function of depth such that the level spacing increases from $1 \mathrm{~m}$ near the surface to $200 \mathrm{~m}$ at $6000 \mathrm{~m}$ (I. Culverwell, personal communication, 2009). This level set was chosen to provide high resolution near the surface for short to midrange forecasting purposes while retaining reasonable resolution at mid-depths for long-term climate studies.

The model's bathymetry (DRAKKAR v3.3) is based on the ETOPO1 data set (Amante and Eakins, 2009) with additional data in coastal regions from GEBCO (General Bathymetric Chart of the Oceans; IOC, 2003). This is a change from the GO1 configuration, which used the DRAKKAR G70 bathymetry based on the lower-resolution ETOPO2 with corrections from satellite-based bathymetry and other sources (Remy et al., 2003). Bottom topography is represented as partial steps (Barnier et al., 2006). The derivation of DRAKKAR bathymetry data sets is described by Barnier et al. (2006). Initially, each model grid cell is assigned the median of all observations falling within the boundaries of that grid cell. The initial estimate is then modified by application of two passes of a uniform Shapiro filter and, finally, hand editing is performed in a few key areas.

The model uses a linear free surface and an energy and enstrophy conserving momentum advection scheme. The horizontal viscosity is bi-Laplacian with a value of $1.5 \times$ $10^{11} \mathrm{~m}^{4} \mathrm{~s}^{-1}$ at the Equator, reducing polewards as the cube of the maximum grid cell dimension: thus at $60^{\circ} \mathrm{N}$ the horizontal viscosity is approximately one-eighth of its value at the Equator. Tracer advection uses a total variance dissipation (TVD) scheme (Zalesak, 1979). Lateral tracer mixing is along isoneutral surfaces with a coefficient of $300 \mathrm{~m}^{2} \mathrm{~s}^{-1}$. The isopycnal mixing scheme of Gent and McWilliams (1990) is not used in this configuration.

With regard to diapycnal mixing processes, the vertical mixing of tracers and momentum is parameterised using a modified version of the Gaspar et al. (1990) turbulent kinetic energy (TKE) scheme (described in Madec, 2008). Unresolved vertical mixing processes are represented by a background vertical eddy diffusivity of $1.2 \times 10^{-5} \mathrm{~m}^{2} \mathrm{~s}^{-1}$, which decreases linearly from $\pm 15^{\circ}$ latitude to a value of $1.2 \times 10^{-6} \mathrm{~m}^{2} \mathrm{~s}^{-1}$ at $\pm 5^{\circ}$ latitude (Gregg et al., 2003) and a globally constant background viscosity of $1.2 \times 10^{-4} \mathrm{~m}^{2} \mathrm{~s}^{-1}$. A parameterization of double diffusive mixing (Merryfield et al., 1999) is included at GO5.0.

Bottom friction is quadratic with an increased coefficient in the Indonesian Throughflow, Denmark Strait and Bab al Mandab regions. An advective and diffusive bottom boundary layer scheme is included (Beckmann and Doescher, 1997). The tidal mixing parameterisation of Simmons et al. (2004) is included with a special formulation for the Indonesian Throughflow (Koch-Larrouy et al., 2008). At GO5.0 a climatological geothermal heat flux (Stein and Stein, 1992) is added as a bottom boundary condition; this was not used at GO1.
The sea ice component is the latest public release of the Los Alamos National Laboratory sea ice model version 4.1 (CICE v4.1; Hunke and Lipscomb, 2010). The model includes elastic-viscous-plastic ice dynamics (Hunke and Dukowicz, 1997), energy-conserving thermodynamics (Bitz and Lipscomb, 1999) and multicategory ice thickness (Bitz et al., 2001). The setup of CICE is the same as in the lowerresolution version of HadGEM3 described by Hewitt et al. (2011) with five sea ice thickness categories. Both GO5.0 and HadGEM3 use the zero-layer Semtner thermodynamics scheme (Semtner, 1976). We also note that in both the GO5.0 and HadGEM3 configurations the sea ice model is not on the same grid as the ocean (sea ice is on the Arakawa B-grid and ocean is on the Arakawa C-grid; Arakawa, 1966) and an interpolation routine is used to couple these model components. As in HadGEM3, the ice and ocean components are combined into a single executable, so there is no need for a coupler.

We shall also discuss the preceding version of the Met Office ocean model, GO1. This was based on NEMO version 3.2 (v3.2) and CICE v4.1, and was implemented on the same grid as GO5.0, with the same surface forcing.

The ocean and ice code are managed using the Subversion code-management software, allowing unique identification of the respective code bases using a code version number. Ocean and ice model code version numbers, compilation keys and name lists are listed in the Appendices A-E.

The model was run on the MONSooN supercomputer, jointly owned by NERC and the Met Office. The ocean was distributed over 480 cores with the MPI communications harness, with CICE running on a single node, and an acceptable throughput of one model year in $6 \mathrm{~h}$ was achieved.

\section{Summary of main physics choices}

The main physics change between GO1 and GO5.0 is a set of changes to the vertical mixing parameters based on the work of Calvert and Siddorn (2013). Vertical mixing in the model is achieved using a turbulent closure scheme with an algebraic mixing length (Gaspar et al., 1990; Madec, 2008). Additionally, the NEMO implementation of the scheme includes a number of parameterisations to represent additional unresolved turbulent processes, including surface wave breaking (Craig and Banner, 1994) and Langmuir turbulence (Axell, 2002). A further parameterisation represents the enhanced mixing due to breaking of near-inertial waves as an additional source of TKE exponentially decaying from the surface. Users of previous versions of the NEMO ORCA025 model have found significant biases, particularly in the midlatitudes, and this has been highlighted as a priority bias to reduce with this configuration. Calvert and Siddorn (2013) explored the sensitivity of the model to realistic ranges of parameters in the TKE scheme using 10-year integrations of NEMO at ORCA $1\left(1^{\circ}\right)$ lateral resolution. As a result of this work they found that altering the vertical length scale for this 
TKE source term (controlled by the parameter $n n \_$htau) from 30 to $10 \mathrm{~m}$ at mid to high latitudes and from 0.5 to $10 \mathrm{~m}$ in the tropics was able to significantly alleviate an excessively diffuse midlatitude thermocline. This was seen to result in reduced summertime mixed layer depths and a significant reduction of near-surface temperature biases at midlatitudes. Additionally, Calvert and Siddorn (2013) suggested that a small increase in the Craig and Banner (1994) wind-wave energy coefficient (controlled by the parameter $r n \_e b b$ ) would be more consistent with theory, but was shown to have a very small impact on model results. Similarly, a minor change in the minimum permitted surface mixing length (controlled by the parameter rn_mxl0) suggested by Calvert and Siddorn (2013) for consistency with other vertical mixing parameters was shown to have a negligible impact.

Convection in the model is parameterised as an enhanced vertical diffusivity of $10 \mathrm{~m}^{2} \mathrm{~s}^{-1}$ for momentum and tracer fields where the water column is unstable. At NEMO v3.2 this enhanced vertical diffusivity was erroneously used in the prognostic equation for the TKE, instead of the vertical diffusivity calculated by the TKE scheme. This was shown to result in a deep bias in wintertime mixed layer depths owing to the non-conservative increase in the calculated TKE. This has since been addressed with NEMO v3.4 and therefore constitutes another difference between GO5.0 and GO1.

Other changes between $\mathrm{GO} 1$ and GO5.0 are changes to other vertical mixing parameters between GO1 and GO5.0 as noted in Table 1; the inclusion of a double diffusive mixing parameterisation at GO5.0; the addition of the bottom boundary layer scheme of Beckmann and Doescher (1997); and the inclusion of a climatological geothermal heating parameterisation at GO5.0.

The inclusion of the particular new processes and parameter choices described above is based on a mixture of recommendations from the recent literature (from low-resolution model studies), and on changes considered desirable on strong theoretical or observational grounds.

\section{Experimental design}

The GO5.0 configuration can be viewed as a set of incremental changes in the model physics relative to the GO1 configuration. In order to evaluate the GO5.0 configuration and to understand the model improvements over GO1, a series of forced ocean-sea ice integrations was performed to assess the effects of each individual change.

\subsection{Model initialisation and forcing}

All of the integrations described here are driven over the period 1976-2005 by the CORE2 surface forcing data set (Large and Yeager, 2009). CORE2 supplies monthly precipitation and daily downward shortwave and longwave radiation which are used to force the model directly, and 6-hourly $10 \mathrm{~m}$ wind, $2 \mathrm{~m}$ air humidity and $2 \mathrm{~m}$ air temperature which are used to compute turbulent air-sea and air-sea ice fluxes during model integration using the bulk formulae proposed by Large and Yeager (2009). The source data for precipitation and radiative fluxes are only available from 1979 and 1984 onward, respectively. Prior to these dates the respective climatologies are used. Climatological monthly runoffs derived from the Dai and Trenberth (2002) climatology are applied along the land mask (Bourdalle-Badie and Treguier, 2006). No diurnal cycle is imposed in the radiative forcing.

Initial conditions for temperature and salinity for all the integrations are obtained from an average of years 20042008 of the EN3 monthly objective analysis (Ingleby and Huddleston, 2007) and the model is started from a state of rest. To avoid unacceptable drifts in salinity and an excessive spin-down of the overturning circulation, the sea surface salinity (SSS) is restored toward monthly mean climatological values: the vertical velocity for restoration $r n \_d e d s$ is set to $-33.33 \mathrm{~mm} \mathrm{day}^{-1} \mathrm{psu}^{-1}$ over the open ocean. Model outputs are archived as successive 5-day means throughout the whole integration and post-processed to monthly means. More details about the model configuration may be found in Storkey et al. (2010), Barnier et al. (2006), and Penduff et al. (2007).

\subsection{Model integrations}

A 30-year integration of GO5.0 was carried out with the final set of modifications and parameter values, from the initial state described above. This was compared with the reference integration, from the same initial state and of the same length, of the pre-existing GO1 model based on NEMO v3.2. To estimate the effect of the code change alone, a further 30-year integration of NEMO 3.4 was made with initial state and all parameters and physics choices identical, or as close as possible, to those of GO1. We compare annual and seasonal means from each of these three integrations and also with observations in the form of the EN3 climatology for subsurface temperature and salinity (Ingleby and Huddleston, 2007), the HadSST3 surface temperature climatology (Kennedy et al., 2011), satellite-derived sea ice extent (Cavalieri et al., 1996, updated yearly), the PIOMAS (Pan-Arctic Ice-Ocean Modeling and Assimilation System) reanalysis for Northern Hemisphere sea ice volume (Zhang et al., 2003), and measured transports through key straits from a variety of observational studies.

An additional set of 10-year simulations was made to attribute changes between GO1 and GO5.0 to individual changes in configuration. These are summarised as follows:

- The bathymetry was upgraded from the original DRAKKAR ORCA025 data set as described in Sect. 2.

- The background vertical diffusivity rn_avt0 and viscosity $r n \_a v m 0$ were increased from $1.0 \times 10^{-5}$ to $1.2 \times$ $10^{-5} \mathrm{~m}^{2} \mathrm{~s}^{-1}$ and from $1.0 \times 10^{-4}$ to $1.2 \times 10^{-4} \mathrm{~m}^{2} \mathrm{~s}^{-1}$, respectively. 
Table 1. Parameter changes between GO1 and GO5.0.

\begin{tabular}{lll}
\hline Parameter & GO1 (where different from GO5) & GO5 \\
\hline Horizontal bi-Laplacian viscosity & Same as in GO5.0 & $-1.5 \times 10^{11} \mathrm{~m}^{4} \mathrm{~s}^{-1}$ \\
Isoneutral Laplacian tracer diffusion & Same as in GO5.0 & $300 \mathrm{~m}^{2} \mathrm{~s}^{-1}$ \\
Background vertical viscosity & $1.0 \times 10^{-4} \mathrm{~m}^{2} \mathrm{~s}^{-1}$ & $1.2 \times 10^{-4} \mathrm{~m}^{2} \mathrm{~s}^{-1}$ \\
Background vertical diffusivity & $1.0 \times 10^{-5} \mathrm{~m}^{2} \mathrm{~s}^{-1}$ & $1.2 \times 10^{-5} \mathrm{~m}^{2} \mathrm{~s}^{-1}$ \\
Energy coefficient for Craig and Banner (1994) & & \\
surface wave breaking parameterisation & 60.0 & 67.83 \\
Length scale for near-inertial wave & $0.5 \mathrm{~m}$ in tropics, & $10 \mathrm{~m}$ everywhere \\
breaking parameterisation & rising to 30 m at midlatitudes & \\
Minimum value of surface mixing length scale & $0.01 \mathrm{~m}$ & $0.04 \mathrm{~m}$ \\
Minimum value of interior mixing length scale & $0.001 \mathrm{~m}$ & $0.01 \mathrm{~m}$ \\
\hline
\end{tabular}

- Changes were made to the TKE scheme parameters $r n \_e b b$ (coefficient of the surface input of TKE), $r n \_m x l 0$ (minimum surface mixing length scale) and $n n \_h t a u$ (changing the TKE penetration depth scale from a constant $10 \mathrm{~m}$ to varying from $0.5 \mathrm{~m}$ at the Equator to $30 \mathrm{~m}$ poleward of $40^{\circ} \mathrm{N}$ and $40^{\circ} \mathrm{S}$ ).

- Geothermal heat flux was applied, as in Stein and Stein (1992) via the parameter nn_geoflx.

- Double diffusion of tracers was added.

- A scheme for a bottom boundary layer as in Beckmann and Doescher (1997) was added.

- The ice model (CICE) was modified to include a salinity-dependent freezing point. The thermal conductivity of the ice was changed from 2.00 to $2.63 \mathrm{~W} \mathrm{~m}^{-1} \mathrm{~K}^{-1}$ and the fixed ice salinity was changed from 4.0 to $8.0 \mathrm{psu}$ (practical salinity units), following Rae et al. (2014).

The attribution study will compare the above experiments with one another, as well as with the v3.2 model GO1 and the original v3.4 integration with the GO1 parameter set. The strategy of adjusting parameters according to individual sensitivity studies may not be the optimal method for finding the most appropriate parameter set, since the parameters and physics choices may interact non-linearly, but resources were insufficient for a systematic investigation of parameter space such as that carried out with HadCM3 by Williamson et al. (2013).

Table 2 summarises the integrations carried out, including the values of the principal parameter changes at each step.

We note that the pair of runs comparing NEMO 3.2 and 3.4 (namely GO1 and N3.4) differ further in one minor respect. The v3.4 parameter $r n \_m x l 0$, the minimum permitted surface mixing length, was erroneously set to 0.001 in the latter experiment to match the value of the parameter $r n \_l m i n$ in v3.2. The latter is an interior minimum length scale in v3.2 but is absent in v3.4, and the equivalent parameter in v3.2 is in fact $r n \_$lmin0, which was set to 0.01 . An additional 10-year integration (N3.4_mx10) similar to N3.4 was performed, with a value of 0.01 : the consequent surface changes were not considered to be significant, with the two simulations being qualitatively the same with mean surface temperature differences in years 6-10 of less than $0.05^{\circ} \mathrm{C}$ everywhere.

\section{Results}

\subsection{Validation of GO5.0 against observations}

\subsubsection{Surface biases and mixed layer depth}

Figure 1 shows the sea surface temperature (SST) and salinity (SSS) errors in years 21-30 of the GO5.0 model, relative to the mean of the Reynolds et al. (2002) and EN3 (Ingleby and Huddleston, 2007) respective monthly climatology over the same period. There is overall a warm bias over most of the global ocean, with a global mean bias of $+0.72{ }^{\circ} \mathrm{C}$, and with the largest biases (of over $1^{\circ} \mathrm{C}$ ) in the tropics, the Southern Ocean, the subpolar North Atlantic and over the separated western boundary currents in the North Atlantic and North Pacific. There are cool biases of $0.25-0.50{ }^{\circ} \mathrm{C}$ extending over much of the subtropical North Atlantic and North Pacific. GO5.0 is too fresh in most of the Atlantic, except in the subpolar gyre, where the salty bias of $0.5-1.0 \mathrm{psu}$ is co-located with the warm bias mentioned above. It is worth noting that the largest surface errors occur at high latitudes, and therefore are perhaps unduly emphasised in the cylindrical projection used in Fig. 1. Generally the regions where there is a surface warm bias (especially in the Southern Ocean and the Pacific) correspond to a positive surface salinity error: these may result from forcing errors, but are not inconsistent with an excessive evaporation from surface waters with a warm bias. The exception is in the Arctic, where there is a positive surface salinity error of up to 2 psu, due to excessive autumn sea ice formation on the Siberian shelves and in the Beaufort Sea (Fig. 1); the reason for this error is unclear, but is most 
Table 2. Summary of integrations carried out. The UM (Unified Model) job ID (identification) is a unique identifier for each run within the Met Office Unified Model system, and allows any configuration to be replicated by another user. The parameters listed are $r n \_a v t O$ (background vertical tracer diffusivity), $r n \_m x l 0$ (minimum surface mixing length scale), and $r n \_e b b$ (coefficient of the surface input of TKE). The switch $n n \_h t a u$ enables a spatially varying TKE penetration depth scale, while $n n \_g e o f l x$ applies an abyssal geothermal heat flux (bathy - bathymetry data set).

\begin{tabular}{llcccccccc}
\hline Run name & UM job ID & NEMO v & rn_avt0 $\times 10^{-5}$ & bathy & $r n \_m x l 0$ & rn_ebb & nn_htau & nn_geoflx & Run (years) \\
\hline GO1 & xexoc & 3.2 & 1.0 & G70 & n/a & 60.0 & 1 & 0 & 30 \\
N3.4 & xhiml & 3.4 & 1.0 & G70 & 0.001 & 60.0 & 1 & 0 & 30 \\
N3.4_mxl0 & xhimq & 3.4 & 1.0 & G70 & 0.01 & 60.0 & 1 & 0 & 30 \\
N3.4_bath & xhimj & 3.4 & 1.0 & GO5 & 0.001 & 60.0 & 1 & 0 & 10 \\
N3.4_vmix & xhkfg & 3.4 & 1.2 & GO5 & 0.001 & 60.0 & 1 & 0 & 10 \\
N3.4_tke & xhkfi & 3.4 & 1.2 & GO5 & 0.04 & 67.83 & 0 & 0 & 10 \\
N3.4_geo & xhimt & 3.4 & 1.2 & GO5 & 0.04 & 67.83 & 0 & 2 & 10 \\
N3.4_DD & xhimp & 3.4 & 1.2 & GO5 & 0.04 & 67.83 & 0 & 2 & 10 \\
N3.4_ice & xhimm & 3.4 & 1.2 & GO5 & 0.04 & 67.83 & 0 & 2 & 10 \\
N3.4_bbl & xhimn & 3.4 & 1.2 & GO5 & 0.04 & 67.83 & 0 & 2 & 10 \\
GO5.0 & xhimo & 3.4 & 1.2 & GO5 & 0.04 & 67.83 & 0 & 2 & 30 \\
\hline
\end{tabular}

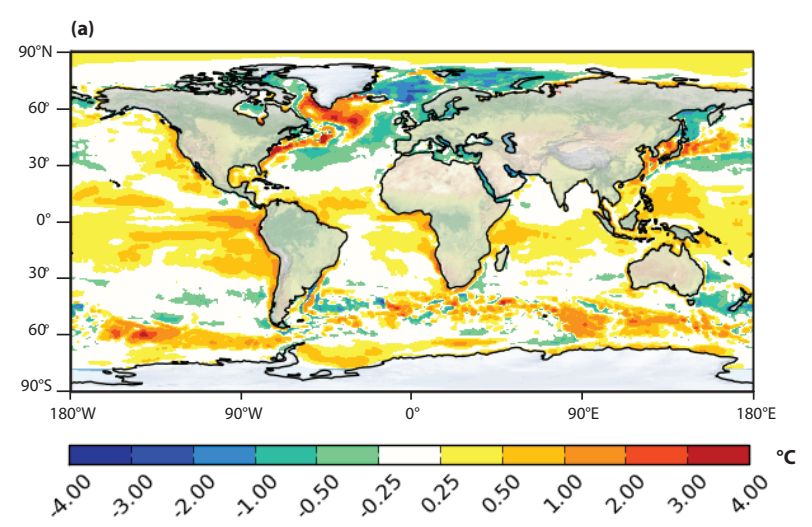

(b)

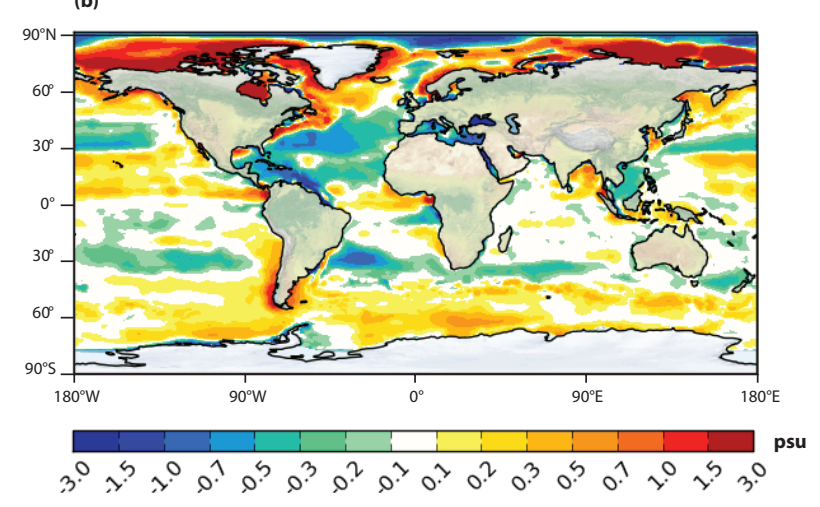

Figure 1. Surface biases in years 1996-2005 of GO5.0: (a) mean surface temperature bias with respect to the Reynolds et al. (2002) climatology, and (b) mean surface salinity bias with respect to the EN3 climatology.

likely to be related to the air temperature and radiative biases in the atmospheric forcing (Barnier et al., 2006). The sea ice biases are discussed further in Sect. 5.1.4.
Figure 2 shows the annual minimum and maximum mixed layer depth (MLD) calculated for years 1996-2005, corresponding to the shallowest depth of the mixed layer in the local hemispheric summer and the deepest mixed layer in the local hemispheric winter, alongside the same quantity from the de Boyer Montégut et al. (2004) climatology. The model's mixed layer depth is calculated from 5-day data using the same criterion of a $0.2^{\circ} \mathrm{C}$ change relative to the surface value as used in the climatology. The ocean data points masked by hatching in the model output (panels a, c) and by white in the climatology (panels b, d) represent the locations where a full annual cycle of observations was not available as a result of sea ice coverage. The GO5.0 model realistically reproduces the spatial patterns of both summer and winter surface mixing: in particular, the regions of wintertime, dense water formation in the North Atlantic and Nordic Seas correspond quite closely to those in the observations, as do the near-zonal bands of deep turbulent mixing in the Southern Ocean (Fig. 2c, d). There is a consistent bias, however, to an unrealistically shallow summer mixed layer over the whole ocean, with maximum values of $30-50 \mathrm{~m}$ in the tropics and Southern Ocean in the model, contrasting with a range of $50-70 \mathrm{~m}$ in the same regions in the climatology (Fig. 2a, b). This is consistent with the warm surface bias in the same regions seen in Fig. 1. Also, the winter mixing in the dense water formation regions in the North Atlantic is much deeper than in the climatology, reaching to over $1000 \mathrm{~m}$ in many instances. The patch of very deep mixing extending from the Weddell Sea eastwards to $50^{\circ} \mathrm{E}$ is also seen in HadGEM1 and HiGEM: in GO5.0 this feature develops after year 20 of the integration, but it does not occur in GO1. It seems to be associated with a gradual modification of the water masses in the region and the development of the extensive polynya visible in Fig. 6c, which together precondition for the deep mixing, but the exact mechanisms are yet unclear. 
(a)

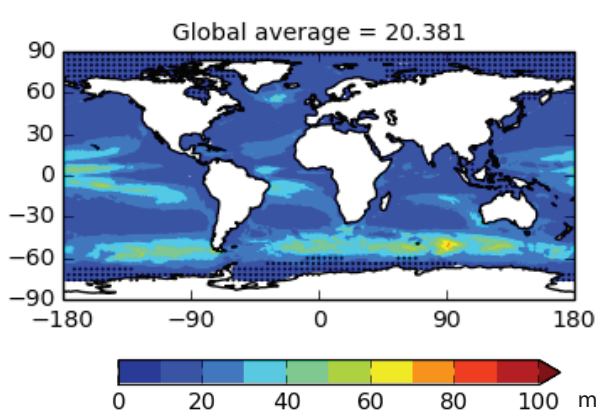

(b)

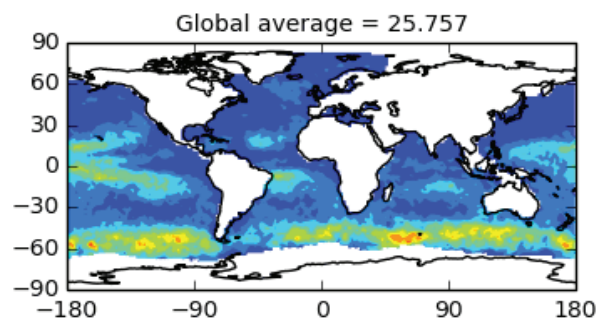

(c)

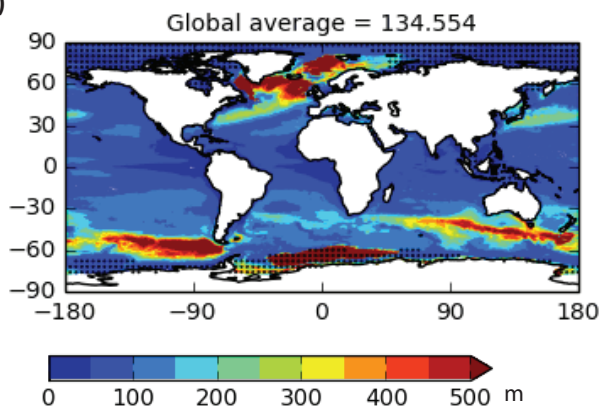

(d)

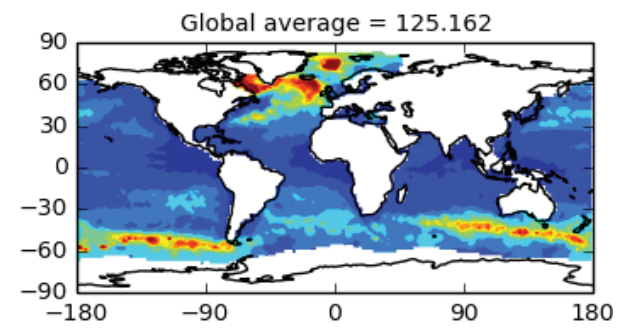

Figure 2. Seasonal cycle of MLD in GO5.0: (a) minimum monthly MLD in years 1996-2005, (b) minimum monthly MLD in the de Boyer Montegut et al. (2004) climatology, (c) maximum monthly MLD in years 1996-2005, and (d) maximum monthly MLD in the de Boyer Montégut et al. (2004) climatology. The hatching in panels a and b correspond to the areas of missing ocean data in panels (c) and (d), where a full annual cycle of MLD is not observed in the de Boyer Montégut climatology.

The simulated deep, winter, mixed layer in the eastern Weddell Sea in the 1990s and 2000s is likely to be unrealistic, although the limited winter data in the area (e.g. Sirevaag et al., 2010) prevents us from making any definitive conclusion. From the conductivity, temperature and depth (CTD) data collected using Weddell seals, Årthun et al. (2013) surmised that the maximum MLD in the region of the Antarctic Bottom Water formation in the southern Weddell Sea is in excess of $500 \mathrm{~m}$, which is consistent with the model results (Fig. 2c).

The surface biases of the model when forced by prescribed surface boundary conditions are to a large degree constrained by the forcing fields, but the subsurface drifts are a stronger test of the model, revealing discrepancies in diapycnal mixing and advection pathways. Figure 3 shows the zonal mean temperature and salinity anomalies in GO5.0 averaged from 1996 to 2005, with reference to the EN3 climatology. The black contours show the zonal mean potential density $\sigma_{0}$, with a $0.5 \mathrm{~kg} \mathrm{~m}^{3}$ contour interval, to illustrate the position of the biases with respect to the main pycnocline. The largest biases are in the top $700 \mathrm{~m}$ of the water column: these include a cold subsurface bias $\left(\sim 2^{\circ} \mathrm{C}\right)$ around Antarctica; a warm salty bias $\left(\sim 1.5^{\circ} \mathrm{C}\right.$ and $\left.0.25 \mathrm{psu}\right)$ between 45 and $60^{\circ} \mathrm{S}$; a warm bias in the tropics of up to $2.5^{\circ} \mathrm{C}$ down to about $200 \mathrm{~m}$; cold, fresh biases in the main thermocline $\left(45^{\circ} \mathrm{S}-45^{\circ} \mathrm{N}\right.$, with maximum discrepancies of $1{ }^{\circ} \mathrm{C}$ and $0.5 \mathrm{psu}$ ); and a warm salty bias in the Northern Hemisphere subpolar gyre regions ( $\left.{ }^{\circ} \mathrm{C}, 0.25 \mathrm{psu}\right)$.
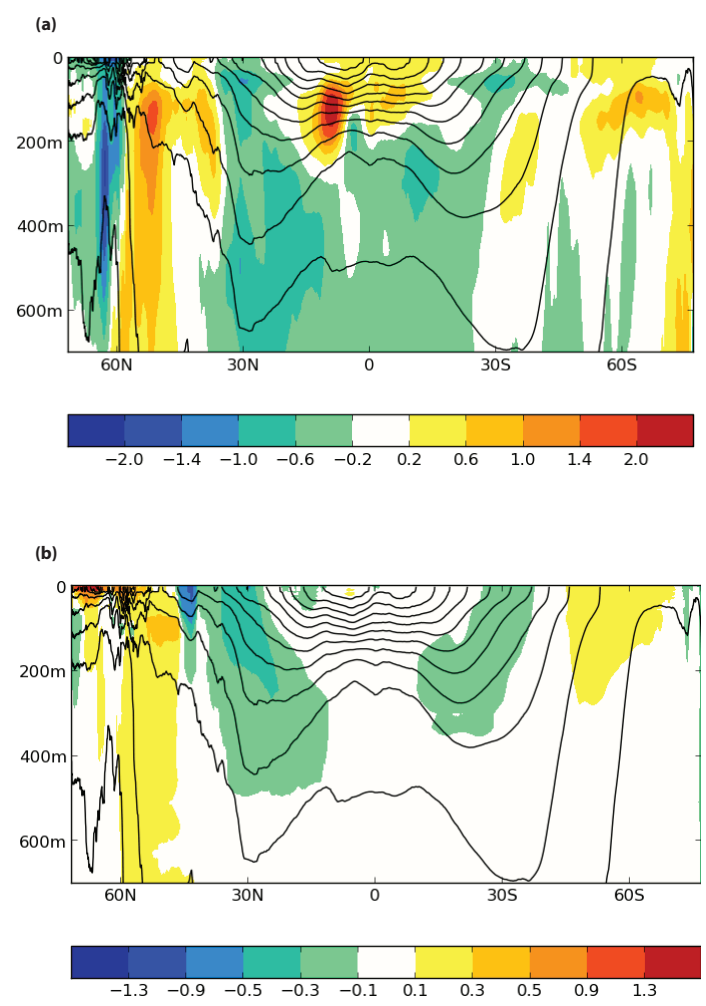

Figure 3. Zonal mean (a) temperature and (b) salinity biases in years 1996-2005 of GO5.0. The solid contours are of the zonal mean potential density $\sigma_{0}$, with a spacing of $0.5 \mathrm{~kg} \mathrm{~m}^{3}$. 


\subsubsection{Atlantic meridional overturning}

Figure $4 \mathrm{a}$ shows a time series of the strength of the Atlantic meridional overturning circulation (AMOC) at $26^{\circ} \mathrm{N}$ for the full 30-year integration of GO5.0, alongside that in GO1. Also shown is the potential density averaged over the upper $200 \mathrm{~m}$ in the central Labrador Sea $\left(55-58^{\circ} \mathrm{N}, 48-50^{\circ} \mathrm{W}\right)$. Figure $4 \mathrm{~b}$ illustrates the meridional overturning stream function in years 1996-2005 in both models. In both GO1 and GO5.0 the overturning circulation reaches a maximum in the second decade of the integration, decreasing by $2-3 \mathrm{~Sv}$ by year 30; the run length is however not sufficient to determine whether the circulation has settled at that stage. In both runs both the AMOC (meridional overturning circulation) and the Labrador Sea density increase over the first decade and decrease later in the second decade, consistent with the hypothesis that the Labrador Sea surface density controls the overturning, although a longer time series would be required to establish a statistically robust correlation. The overturning strength at $26^{\circ} \mathrm{N}$ in the final decade is between 21 and $22 \mathrm{~Sv}$, which is significantly stronger than the value of $18.5 \pm 1 \mathrm{~Sv}$ observed between 2004 and 2008 by the RAPID WATCH/MOCHA array (McCarthy et al., 2012). Interestingly, the downward trend we see in the last decade of the model runs $\left(\sim 2-3 \mathrm{~Sv}\right.$ decade $\left.{ }^{-1}\right)$ is similar to that recently reported from the RAPID array (Smeed et al., 2014). The modelled annual means for 2 years overlapping the observations, namely 2004 (19 Sv) and 2005 (20 Sv) match well with the observations (17.8 and $20.1 \mathrm{~Sv}$, respectively), and the strength of the modelled AMOC over the latter decade of the run is entirely plausible, particularly since recent studies indicate that a substantial fraction of the variability in the strength of the AMOC originates from surface forcing (Roberts et al., 2013; Blaker et al., 2014). We cannot expect the model to simulate the measured AMOC perfectly, since a significant fraction of the AMOC variability is inherently unpredictable, arising as a consequence of the baroclinic wave field and mesoscale eddy field (Hirschi et al., 2013; Thomas and Zhai, 2013). Hirschi et al. (2013), performed forced $1 / 4^{\circ}$ simulations similar to those described in this paper with different initial conditions: in the simulations of Hirschi et al. (2013) about $70 \%$ of the AMOC variability is determined by the surface-forcing, and $30 \%$ from intrinsic ocean variability. We expect this to be an underestimation, since our model configuration is eddy-permitting, rather than eddy-resolving. The question of the physical processes contributing to AMOC variability in models and observations (for example, Ekman transport, advection of density anomalies and Rossby waves) is complex and has been explored in a number of recent papers (e.g. Sinha et al., 2013; Roberts et al., 2013; Robson et al., 2014), but is beyond the scope of the current paper. We note that the modelled annual means quoted here are January-December, whilst the observational array figures are April-March. (a)

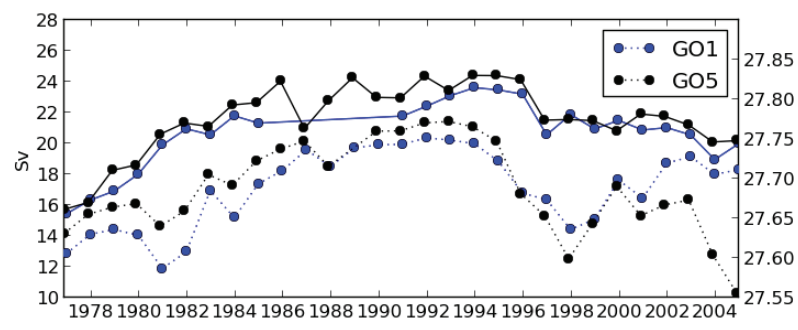

(b)

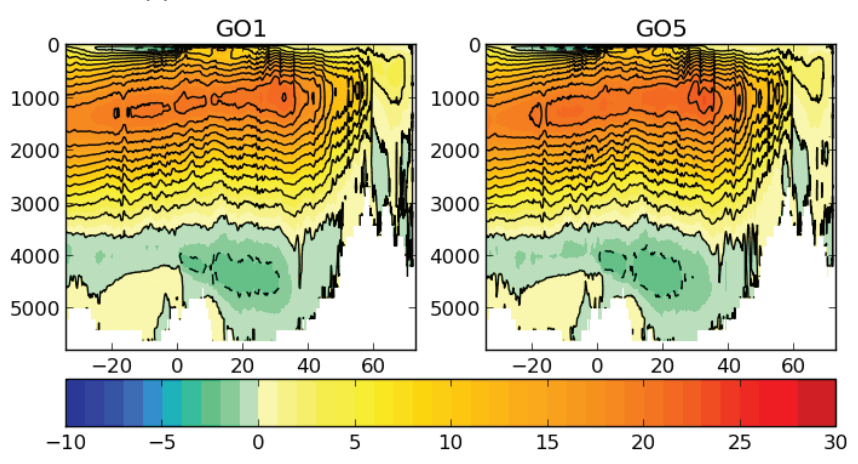

Figure 4. (a) Time series of annual mean AMOC at $26^{\circ} \mathrm{N}$ in GO1 and GO5.0, with the potential density $\sigma_{0}$ in the upper $200 \mathrm{~m}$ in the central Labrador Sea; and (b) mean Atlantic overturning stream function in years 1996-2005 of GO1 (left) and GO5.0 (right). Note that velocity data are missing in years 1986-1990 of GO1.

Figure $4 \mathrm{~b}$ also shows that the depth of the North Atlantic Deep Water (NADW) return flow is too shallow. At $26^{\circ} \mathrm{N}$ the depth of the NADW return flow (usually defined as the depth of the zero contour in the stream function) is around $3500 \mathrm{~m}$ for most of the model run compared to deeper than $4000 \mathrm{~m}$ in the RAPID array data. This is a common bias in many ocean GCMs (global circulation models) using depth coordinates, and is usually attributed to spurious mixing of overflow waters as they descend from passages in the Greenland-Iceland-Scotland ridges to the deep ocean (Saunders et al., 2008; Danabasoglu et al., 2010). It is worth noting that substantial variation in the depth profile can arise from the method used to compute the overturning. Computing the overturning from a model using the RAPID array methodology and assuming a geostrophic reference depth of $4740 \mathrm{~m}$ can yield a transport profile much more similar to the observations at $26^{\circ} \mathrm{N}$ than integrating the model velocities (Roberts et al., 2013).

The increase in the AMOC over the first decade of the model run is a phenomenon often seen in ocean GCMs using mixed surface boundary conditions in which the highlatitude oceans become overly sensitive to salinity perturbations (Rahmstorf and Willebrand, 1995; Lohmann et al., 1996; Greatbach and Peterson, 1996; Griffies et al., 2009; Yeager and Jochum, 2009). In the GO5.0 model run, an initial 
error in the path of the NAC causes warm, salty water to be advected into the subpolar gyre where it joins the Greenland current and enters the Labrador Sea. The prescribed surface air temperature causes excessive surface heat loss in the Labrador Sea, increasing the density of the surface waters and leading to excessive deep water formation in this region. The increase in the AMOC causes more warm, salty water to be advected into the subpolar gyre in a positive feedback. Yeager and Jochum (2009) show that stronger sea surface salinity restoration can reduce this feedback mechanism by reducing the surface salinity in the Labrador Sea. This improvement, however, comes at the expense of realistic interannual variability in the global climate.

\subsubsection{Critical sill and strait transports}

Table 3 lists the volume transports through the major straits and across critical sills, evaluated from the model velocities averaged over the last 10 years of the 30 -year integrations of GO1 and GO5.0, together with recent observed estimates and their sources. The sign convention is positive for northward and eastward flow. Overall, the models simulate these transports acceptably: in particular, the Drake Passage throughflow is much closer to observations than those in the lower-resolution coupled models HadCM3 and HadGEM1, both of which at $\sim 200 \mathrm{~Sv}$ (Johns et al., 2006) are unrealistically strong. HadGEM2 (Collins et al., 2008) gave a comparable simulated Drake Passage transport of $\sim 140 \mathrm{~Sv}$ (Meijers et al., 2012). In contrast to these aforementioned coupled models, the $1 / 4^{\circ}$ resolution of the ORCA025 grid allows the present model to at least approach an explicit resolution of the narrower passages: in particular, it can be seen that both GO1 and GO5.0 have transports through the Bering Strait of well within a factor of two of the observed values.

The Indonesian Throughflow is too strong in both GO1 and GO5.0, which may be due to insufficient enhancement of the tidal mixing in this region (Koch-Larrouy et al., 2008).

Comparing the model-derived and observation-based estimates of the Arctic-Atlantic exchanges across the Greenland-Scotland Ridge, through the Fram and Davis straits, and through the Barents Sea shows that in both 30year model runs the volume transports are within 10-20\% of the observed long-term mean values and within the range of the observational uncertainties, except for the Denmark Strait overflow where the model estimates are $33 \%$ (GO1) and $45 \%$ (GO5.0) higher than the observational estimate (Table 3). Although the simulated net outflow from the Arctic Ocean, of $4.8 \mathrm{~Sv}$ in GO1 and $4.6 \mathrm{~Sv}$ in GO5.0, is very close to the observed value of $4.6 \mathrm{~Sv}$, the model shows a different partitioning of the exports west and east of Greenland: the simulated flow through the Canadian Archipelago is larger than the export through the Fram Strait, which is opposite to the observations. The bias is stronger in summer than in winter and is due to excessive Ekman convergence in the Beaufort Sea; this in its turn is caused by the summer sea ice extent being too low (see next section). The simulated Pacific inflow in the Bering Strait is higher than in the observations, even considering the recent update in the latter estimate (Woodgate et al., 2012). The simulated northward ocean velocities in the strait are about $35 \%$ higher then those observed at the long-term moorings (Clement Kinney et al., 2014). Aagaard et al. (2006) suggested that the flow through the Bering Strait is partly driven by the local wind and partly by the steric height difference between the Bering and Chukchi seas. The latter is caused by the fresher, warmer waters present to the south of the strait and colder, more saline waters to the north of the strait (Aagaard et al., 2006). In the model the positive bias in salinity in the Chukchi Sea and the eastern Arctic (Fig. 1b) increases the steric height gradient from the North Pacific to the Arctic Ocean, increasing the northward flow through the Bering Strait. The stronger Pacific inflow brings extra heat into the Arctic Ocean, which may contribute to the excessive sea ice melting.

Overall, both runs, GO1 and GO5.0, present more vigorous northward flow of the Atlantic water than is observed ("Total Greenland-Scotland inflow" in Table 3 is a proxy for this) and stronger-than-observed return overflows across the Greenland-Scotland Ridge: the combined overflows in the Denmark Strait and in the opening between Iceland and the Faeroes and between the Faeroes and Scotland are $6.3 \mathrm{~Sv}$ from the data, 9.3 Sv in GO1 and 8.3 Sv in GO5.0. This is also consistent with the stronger simulated AMOC compared to observations.

It should be noted that the observational estimates of the exchange transports into and out of the Arctic should be treated with caution. First, in all straits, except for the moorings in Bering Strait, the hydrographic section in the Fram Strait and the one in the Barents Sea between Norway and Bjørnøya (Barents Sea opening), uninterrupted records from current meter moorings are no longer than 2 years. This aliases interannual variations and introduces large uncertainties in the observational transport estimates. Secondly, the instruments were not positioned in the top $50 \mathrm{~m}$ or on shallow shelves, in order to prevent the moorings being damaged by sea ice keels. Lastly, the distances between the moorings were too great to resolve mesoscale variability of the flows and in Bering Strait the transports were derived from velocity measurements obtained from three separate moorings (e.g. Woodgate et al., 2012). All this introduces spatial aliasing in the interpolating procedures and uncertainties in the transports. For a detailed discussion of uncertainties in observed transports, please refer to e.g. Curry et al. (2011) and Olsen et al. (2008). It also should be noted that, while the model's standard deviations in the table represent variability of the transports on synoptic to interannual timescales, the standard deviations of the observational estimates include uncertainty inherent in the estimation methods as well as the variability of the transports, thus rigorous comparison of the variability in the model and data requires additional analysis, not presented here. 
Table 3. Volume transports (Sv), observed and model mean values and their standard deviations. Model values are means over the last 10 years of the 30-year spin up. Model standard deviations are obtained from the 5-day averages. Sign convention is positive northwards and eastwards, and is negative southwards and westwards.

\begin{tabular}{|c|c|c|c|}
\hline Location & Observed value & GO1 & GO5.0 \\
\hline $\mathrm{AMOC}$ at $26^{\circ} \mathrm{N}$ & $18.5 \pm 1^{\mathrm{a}}$ & $21.0 \pm 4.2$ & $22.0 \pm 4.2$ \\
\hline Barents Sea opening net & $2.8 \pm 0.6^{\mathrm{b}, \mathrm{c}, \mathrm{d}}$ & $3.3 \pm 2.0$ & $3.0 \pm 2.0$ \\
\hline Fram Strait net & $-2.3 \pm 4.3^{\mathrm{e}}$ & $-1.9 \pm 2.4$ & $-1.6 \pm 2.3$ \\
\hline Denmark Strait net & $(-6.0 \text { to }-3.6)^{\mathrm{d}}$ & $-3.4 \pm 3.3$ & $-3.3 \pm 3.3$ \\
\hline Denmark Strait overflow ${ }^{\mathrm{m}}$ & $-2.9 \pm 0.6^{\mathrm{f}}$ & $-5.3 \pm 2.9$ & $-4.34 \pm 2.1$ \\
\hline Iceland-Faeroes net & $2.8 \pm 0.5^{\mathrm{g}}$ & $2.72 \pm 1.2$ & $2.6 \pm 1.2$ \\
\hline Iceland-Faeroes overflow ${ }^{\mathrm{m}}$ & $-1.0 \pm 0.5^{f}$ & $-0.9 \pm 0.5$ & $-0.9 \pm 0.5$ \\
\hline Faeroes-Scotland net & $1.8 \pm 0.5^{\mathrm{g}}$ & $1.4 \pm 2.3$ & $1.7 \pm 2.3$ \\
\hline Faeroes-Scotland overflow ${ }^{\mathrm{m}}$ & $-2.4 \pm 0.4^{\mathrm{f}}$ & $-3.1 \pm 0.8$ & $-3.1 \pm 0.9$ \\
\hline Total Greenland-Scotland inflow ${ }^{\mathrm{n}}$ & $8.5 \pm 1.0^{\mathrm{g}}$ & $9.3 \pm 1.8$ & $10.0 \pm 1.7$ \\
\hline Bering Strait net & $0.8\left[1.1^{\mathrm{l}}\right] \pm 0.2^{\mathrm{i}}$ & $1.3 \pm 0.9$ & $1.4 \pm 0.9$ \\
\hline Davis Strait net ${ }^{\mathrm{O}}$ & $-2.6 \pm 1.0$ to $-2.3 \pm 0.7^{\mathrm{e}, \mathrm{h}}$ & $-2.9 \pm 1.2$ & $-3.0 \pm 1.1$ \\
\hline Drake Passage & $135 \pm 20^{\mathrm{j}}$ & $119 \pm 8$ & $124 \pm 8$ \\
\hline Indonesian Throughflow & $-15 \pm 4^{\mathrm{k}}$ & $-19.7 \pm 5.4$ & $-19.8 \pm 5.5$ \\
\hline
\end{tabular}

Key: ${ }^{\text {a }}$ McCarthy et al. (2012), ${ }^{\mathrm{b}}$ Gammelsrod et al. (2009), ${ }^{\mathrm{c}}$ Skagseth et al. (2008), ${ }^{\mathrm{d}}$ Aksenov et al. (2010), ${ }^{\mathrm{e}}$ Curry et al. (2011), ${ }^{\mathrm{f}}$ Olsen et al. (2008), ${ }^{\mathrm{g}} \emptyset$ sterhus et al. (2005), ${ }^{\mathrm{h}}$ Cuny et al. (2005), ${ }^{\mathrm{i}}$ Woodgate et al. (2012), ${ }^{\mathrm{j}}$ Cunningham et al. (2003),

${ }^{\mathrm{k}}$ Sprintall et al. (2009), ${ }^{1}$ climatological transport with the estimate for 2011 in parenthesis, ${ }^{\mathrm{m}}$ southward transport of waters with $\sigma_{\theta}>27.8,{ }^{\mathrm{n}}$ Atlantic inflow derived as the residual flow after subtracting the southward transport of waters with $\sigma_{\theta}>27.8$,

${ }^{\circ}$ including transports on the West Greenland shelf.

\subsubsection{Sea ice}

In Fig. 5 time series of the sea ice extent and ice concentration in the Northern Hemisphere and Southern Hemisphere are compared with products from passive microwave satellites SSMR/I (special sensor microwave/imager) and AVHRR (advanced very high resolution radiometer; Cavalieri, 1996, updated 2013). In the Northern Hemisphere the simulated annual mean of $11.2 \times$ $10^{6} \mathrm{~km}^{2}$ and the amplitude of the seasonal cycle of $7 \times$ $10^{6} \mathrm{~km}^{2}$ are in good agreement with the data $\left(12.4 \times 10^{6} \mathrm{~km}^{2}\right.$ and $5.8 \times 10^{6} \mathrm{~km}^{2}$, respectively), suggesting good model skill in simulating sea ice extent (Fig. 5a), although the model underestimates summer sea ice extent. The simulated and observed interannual trends also agree. Figure $5 \mathrm{~b}$ compares the modelled Arctic sea ice volumes with these derived from the PIOMAS reanalysis (Zhang et al., 2003). Simulated sea ice volumes are about $60 \%$ of those observed through the annual cycle, with winter (DJF - December-January-February) biases of around $30 \%$ and in summer (JJA - June-JulyAugust) of around $50 \%$. Despite this bias, the multidecadal trends in the modelled and observed sea ice extents are comparable, showing sea ice extent decline at a rate of $-44 \times$ $10^{3} \mathrm{~km}^{2}$ year $^{-1}$ and $-45 \times 10^{3} \mathrm{~km}^{2}$ year ${ }^{-1}$, respectively. In the Southern Hemisphere the modelled sea ice extent is again in good agreement with observations (Fig. 5c), but with a moderate negative summer bias. At present no published sea ice volume time series are available for Antarctica, rendering formal validation of the model skills in simulating sea ice volumes in the Southern Hemisphere impossible. However, comparing simulated sea ice thicknesses around Antarctica for the period 1996-2005 with the Antarctic Sea Ice Processes and Climate (ASPeCt) data (Worby et al., 2008) for the same period, we conclude that the simulations underestimate long-term mean annual sea ice thickness by about $15 \%$ $(0.76 \mathrm{~m}$ in the model and $0.89 \mathrm{~m}$ in the observations). The annual cycle in the model is in good agreement with the observations, with the maximum ice thickness $(1.06 \mathrm{~m}$ and in the model and $1.02 \mathrm{~m}$ in the observations) occurring in the austral summer (DJF) and minimum ice thickness $(0.58 \mathrm{~m}$ in the model and $0.60 \mathrm{~m}$ in the observations) in the austral winter (JJA). The simulated sea ice extent trend in the Southern Hemisphere is negative and around $-58 \times 10^{3} \mathrm{~km}^{2}$ year $^{-1}$, in contrast to the positive trend of $13 \times 10^{3} \mathrm{~km}^{2} \mathrm{year}^{-1}$ in the observations. The negative trend in Antarctic sea ice extent is a common feature of global ocean models, and is attributed by Holland and Kwok (2012) to biases in the surface winds around Antarctica in the forcing data.

Comparison between the simulated sea ice concentration fields and those from the HadISST (Hadley Centre Sea Ice and Sea Surface Temperature) observational data set (Rayner et al., 2003) show that the simulated winter sea ice distribution in both hemispheres is realistic (Fig. 6a-d), although we note that there is a tongue of reduced ice cover extending eastward from the central Weddell Sea, which has also been seen in HadGEM1 and the higher-resolution HiGEM (Shaffrey et al., 2009), and which corresponds to the very deep winter mixing described in Sect. 5.1.1. The summer sea ice concentration in the model is lower than in the data (Fig. 6e-h). In the Arctic Ocean this is likely to be caused by 
(a)

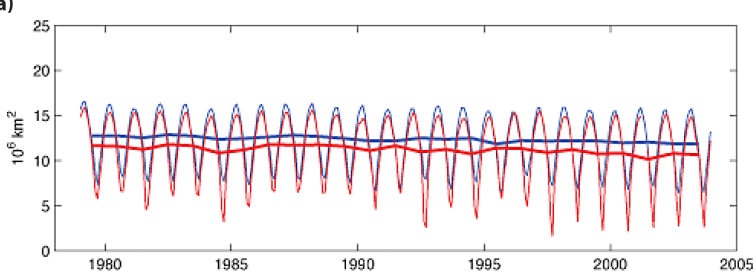

(b)

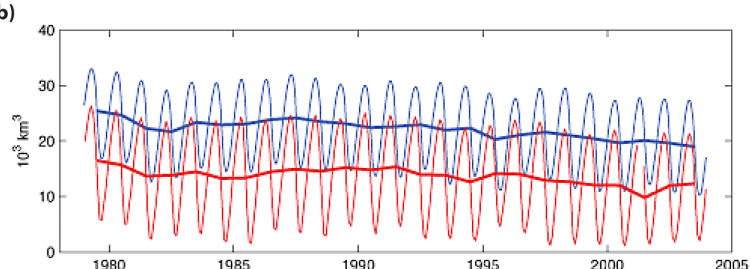

(c)

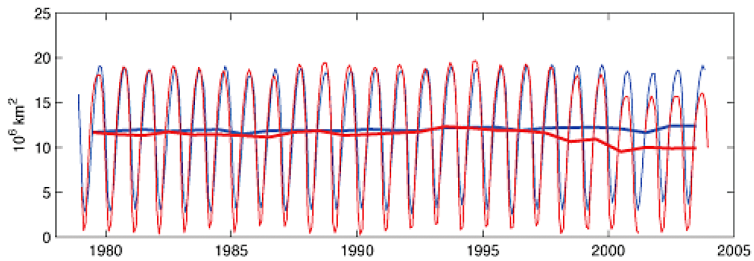

(d)

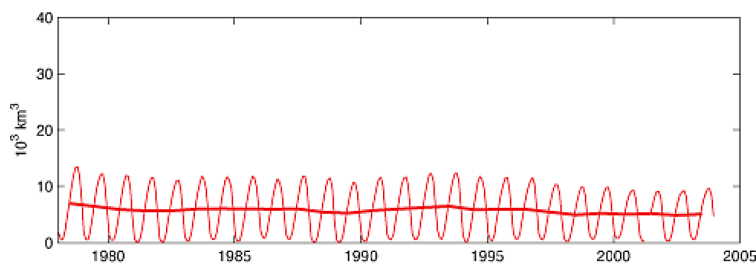

Figure 5. Time series of integrated sea ice properties in GO5.0 (red) and from observational estimates (blue): (a) Arctic mean ice extent, (b) Arctic mean ice volume, (c) Antarctic mean ice extent, and (d) Antarctic mean ice volume.

the negative bias in the sea ice thickness, which in turn results in lower ice strength, faster ice drift toward the Canadian Arctic archipelago and thus increased divergence of sea ice in the central Arctic Ocean. This, combined with the increased sea ice melting in summer, due to exposure of the ocean surface to the atmospheric heat, could sustain the lower thicknesses in the Arctic throughout the year. In the present forced simulations, the summer sea ice bias primarily affects polar regions and has a moderate effect on the global ocean circulation. However, in a fully coupled model atmospheric dynamics might cause a significant effect on regions remote from the ice-covered oceans.

\subsection{Comparison of GO1 and GO5.0}

As shown in Fig. 1, GO5.0 shows large-scale surface biases, which are nevertheless not untypical of comparable forced ocean models and are in part due to forcing errors. It is worth noting that the impact on the coupled model of the vertical (a)

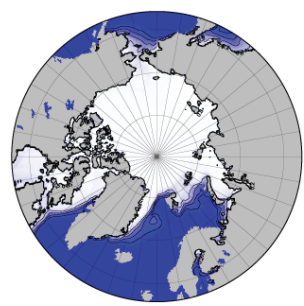

(c)

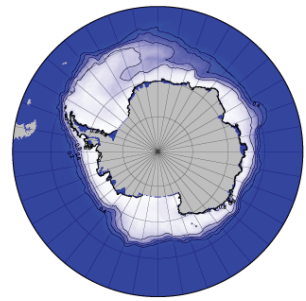

(b)

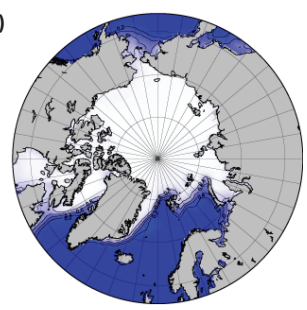

(d)

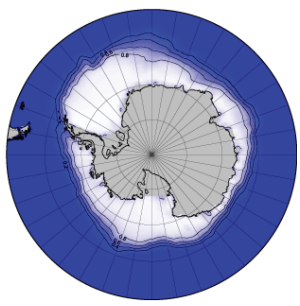

Ice Fraction

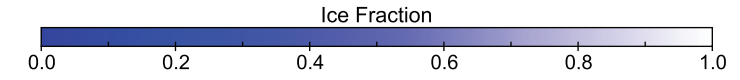

(e)

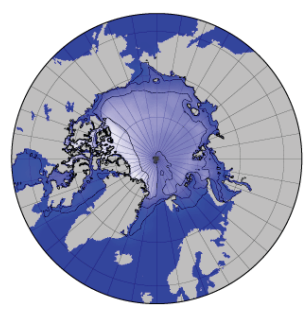

(g)

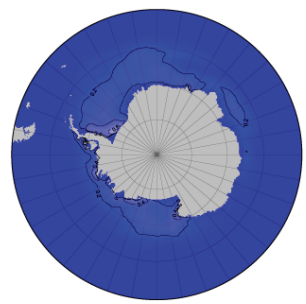

(f)

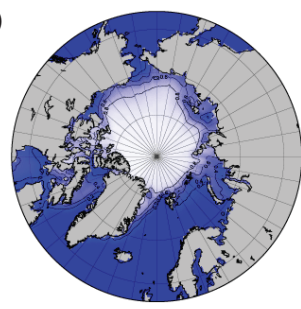

(h)

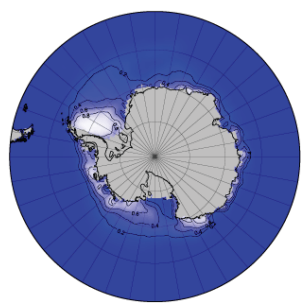

Figure 6. High-latitude sea ice extent in GO5.0 and in the HadISST observational data set: Arctic winter (DJF) ice extent in (a) GO5.0 and (b) observations; Antarctic winter (JJA) ice extent in (c) GO5.0 and (d) observations; Arctic summer (JJA) ice extent in (e) GO5.0 and (f) observations; and Antarctic summer (DJF) ice extent in (g) GO5.0, and (h) observations.

mixing changes is expected to be greater. We shall show in this section that, while the surface biases in the GO1 configuration are similar in most regions of the ocean to those already described in GO5.0, there are significant improvements in the subsurface drifts and the representation of the annual cycle of surface temperature in GO5.0, both of which are likely to lead to improvements in climate simulations.

\subsubsection{Subsurface drifts}

Figure 7 shows the global zonal mean temperature and salinity drifts of GO1 and GO5.0, defined as the difference between the respective mean for each year and the corresponding mean for the first year of integration, from the surface 

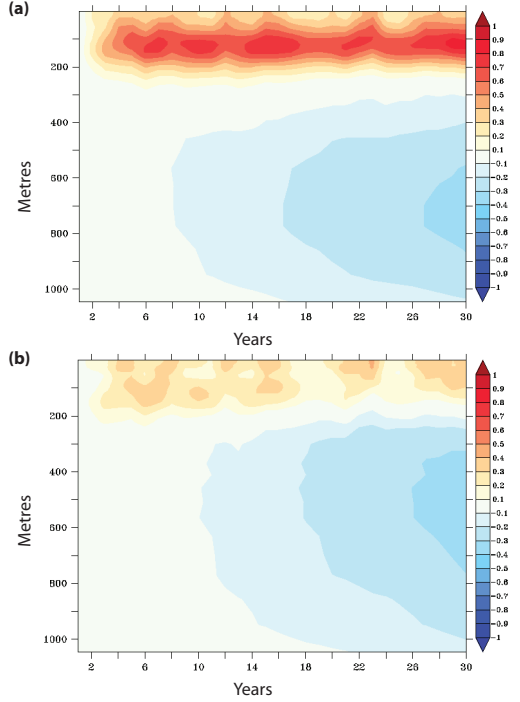

(c)
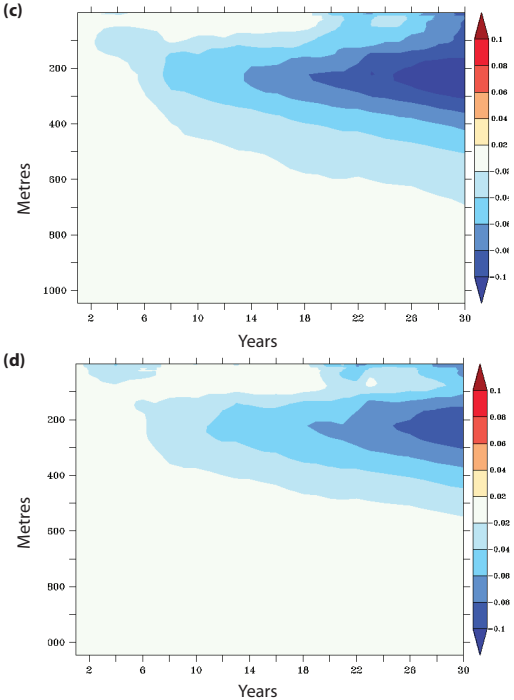

Figure 7. Subsurface drifts, defined as the difference of the horizontally averaged annual mean in any year from that in the first year of integration, as a function of depth: (a) GO1 temperature drift, (b) GO5.0 temperature drift, (c) GO1 salinity drift, and (d) GO5.0 salinity drift.

to a depth of $1000 \mathrm{~m}$. We note that the drifts in both models are an order of magnitude larger that the comparable trends in the EN3 climatology (not shown). The temperature field in the upper $300 \mathrm{~m}$ reaches a quasi-equilibrium state after about 5 years of integration. Both models warm in the above depth range, with a maximum at about $120 \mathrm{~m}$ depth: in GO1 the maximum is up to $0.6^{\circ} \mathrm{C}$, while in GO5.0 the warming at the same depth only reaches $0.3^{\circ} \mathrm{C}$. Below $300 \mathrm{~m}$ both models cool, with a similar maximum rate at $600 \mathrm{~m}$ of around $-0.12{ }^{\circ} \mathrm{Cdecade}^{-1}$. The salinity, by contrast, does not equilibrate, even in the upper ocean, and both GO1 and GO5.0 freshen globally, with a maximum rate at $200 \mathrm{~m}$ of $0.036 \mathrm{psu} \mathrm{decade}^{-1}$ in the former and $0.025 \mathrm{psu} \mathrm{decade}^{-1}$ in the latter. We note that the warm error in GO5.0 is mainly in the northwestern Atlantic and Southern Ocean, while this model is generally too fresh at the surface, with the exception at the Arctic (where there is a large salty surface bias of 1-2 psu), and the Southern Ocean. There is also interannual variability in the globally averaged surface temperature and salinity in the upper $200 \mathrm{~m}$ : this is not well correlated with that of the surface variability, so it is not likely to be a direct signature of the ENSO cycle.

It is interesting to relate the drifts in GO1 and GO5.0 to those over the first 30 years of HadGEM1 (Johns et al., 2006) and in CHIME and HadCM3 (Megann et al., 2010). All these except for CHIME (which uses a hybrid isopycniccoordinate ocean, in contrast to the depth-coordinate ocean model in the other three) have a pronounced freshening in the upper ocean that steadily penetrates into the interior, and this is likely to be a consequence of the numerical diapycnal mixing typical of this model type (Griffies et al., 2000). HadCM3 and HadGEM1 (which shared an ocean model, albeit on a slightly different grid) similarly had a negative surface temperature error over most of the ocean, offset in HadCM3 by a warm bias in the Southern Ocean, while CHIME had a warm surface error, consistent with a reduced drawdown of heat by numerical mixing.

\subsubsection{Seasonal cycle of surface temperature and mixed layer depth}

Figure 8 shows the mean biases of the sea surface temperature in GO1 and GO5.0 with respect to the interannual Reynolds et al. (2002) climatology in the boreal winter and boreal summer seasons, defined as the DJF and JJA periods respectively. It is clear that both configurations have substantial biases in the time-averaged surface fields, and as with the 10-year mean fields discussed in Sect. 5.1.1, in many regions these biases are very similar: for example, the tropics and Southern Ocean are generally too warm in both configurations, while the northern high latitudes are generally too cold, and there is a warm error in the subpolar North Atlantic with maximum values of $3-4{ }^{\circ} \mathrm{C}$ in the boreal winter. There are regions where the seasonal biases in GO1 are smaller than in GO5.0: for example, the cold boreal winter error in the subtropical North Atlantic is larger in GO5.0 south of the separated Gulf Stream (Fig. 8a, b), and in the Southern Ocean there is a substantial coherent warm error in GO5.0 in the austral summer that is not present to the same extent in GO1. Overall, however, there are large-scale reductions in seasonal bias, particularly in the northern summer (JJA) season: the cold errors in the North Atlantic and North Pacific are substantially reduced in GO5.0, as are the warm biases in the tropics and the Southern Ocean. To quantify the improvements, the global rms(root mean square) SST error in 

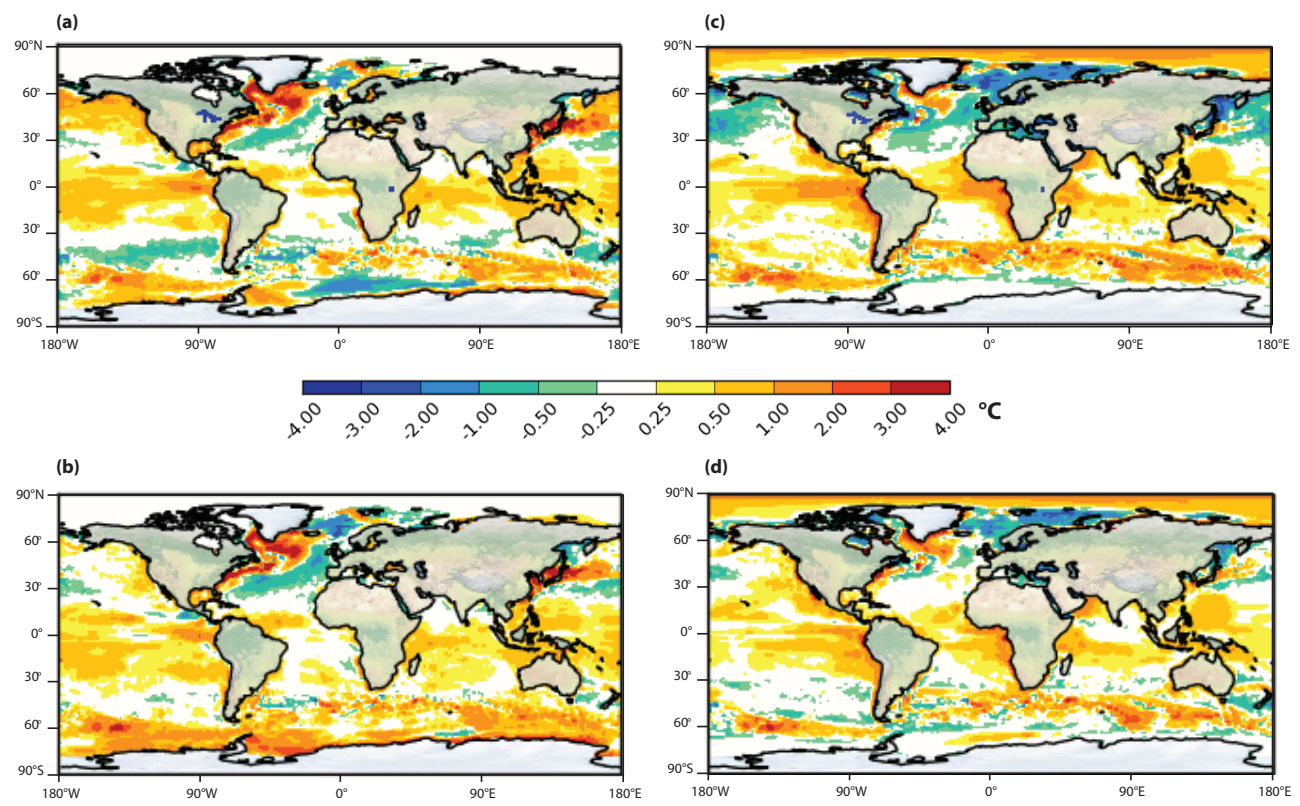

Figure 8. Seasonal SST biases against Reynolds et al. (2002) climatology: boreal winter (DJF) biases in (a) GO1 and (b) GO5.0, and boreal summer (JJA) biases in (c) GO1 and (d) GO5.0.

the boreal summer (JJA) is reduced from $0.93{ }^{\circ} \mathrm{C}$ in $\mathrm{GO} 1$ to $0.65^{\circ} \mathrm{C}$ in GO5.0, while the global mean boreal winter (DJF) error is reduced from 0.79 to $0.67^{\circ} \mathrm{C}$.

To illustrate the latitude dependence of the large-scale seasonal biases in GO1 and GO5.0, Fig. 9 shows latitude-time plots of the zonally averaged surface temperature bias (referred to the climatology of Reynolds et al., 2002) and MLD error (referred to the data of de Boyer Montegut et al., 2004) in GO1 and GO5.0. This shows more clearly that the boreal summer warm bias in the tropics is reduced in GO5.0, as is also the large summer cold bias in the northern subtropics. As we have already noted, GO5.0 shows systematic biases in both the minimum and maximum MLD (Fig. 2): specifically, in both hemispheres winter mixed layers are generally too deep, while summer mixed layers are generally too shallow. The main difference between GO1 and GO5.0 is that mixed layer depths are generally shallower in GO5.0, leading to increased stratification and hence the warmer summer surface temperatures, especially in the Southern Ocean, seen in Figs. 8b and 9a. The winter MLD biases, in contrast, are generally reduced in GO5.0.

\subsubsection{Surface heat fluxes}

Although the model uses the CORE2 forcing data set, the use of bulk formulae to calculate some of the components of the heat flux means that the actual heat input to the ocean will be slightly different from the climatological field, and will reflect the surface temperature biases of the model. Figure 10a shows the zonal mean net downward surface heat flux in GO5.0 and GO1, alongside the corresponding mean from the
CORE2 data set, while Fig. 10b shows the difference in the surface heat flux between the two model configurations. The physics changes between GO1 and GO5.0 can be seen to lead to changes in the heat flux that are generally small compared with the difference between the models and the climatology. In tropical and subtropical latitudes the zonal mean surface flux in both model integrations is within $5-10 \mathrm{~W} \mathrm{~m}^{-2}$ of the observations, while the excessive heat loss of up to $20 \mathrm{~W} \mathrm{~m}^{-2}$ between 60 and $70^{\circ} \mathrm{N}$ and south of $60^{\circ} \mathrm{S}$ in both cases may be linked with the warm biases described in Sect. 5.1.1 in these latitude ranges. The regional differences in heat flux between the model versions correspond closely to differences in surface temperature, with the reduction in the warm bias in the tropical Atlantic and Pacific from GO1 to GO5.0 (visible in Fig. 9a and b) leading to an increase of up to $25 \mathrm{~W} \mathrm{~m}^{-2}$ in the heat flux into the ocean in these regions, and similarly the reduction in wintertime cold bias in subpolar latitudes seen in Fig. 9 corresponds to a decreased heat loss over the Labrador Sea. In the Southern Ocean the increased surface flux error is larger in GO5.0 relative to that in GO1, and is linked to the intense Weddell Polynya that develops in in GO5.0.

\subsection{Attribution of changes}

In this section we refer to the experimental design described in Sect. 4, where a series of shorter (10-year) integrations are made. The model code is first upgraded from NEMO v3.2 to $\mathrm{v} 3.4$, then other changes are progressively made within v3.4, to attribute the most significant changes in model fields to specific changes in the model physics. These changes are summarised in Table 2. We compare the mean fields in the 

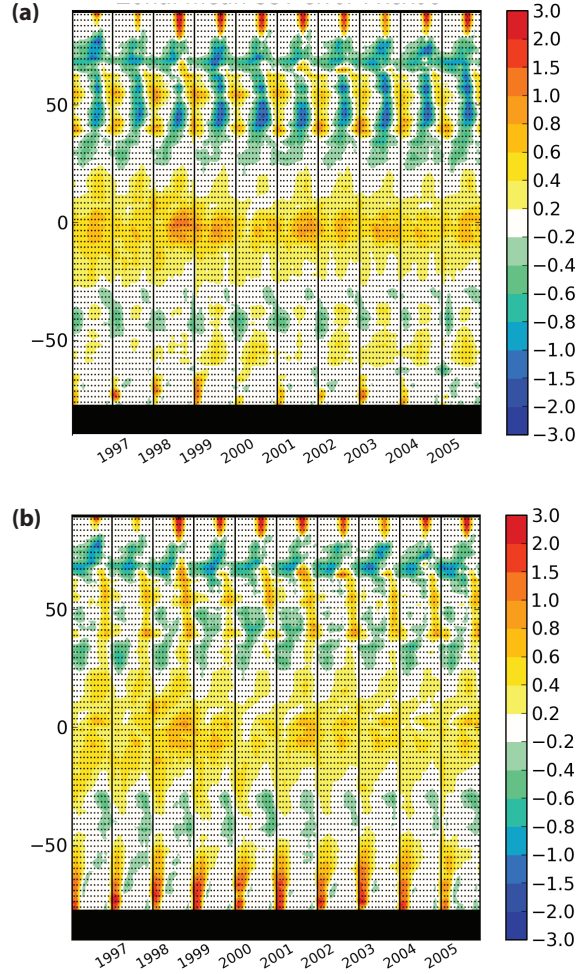
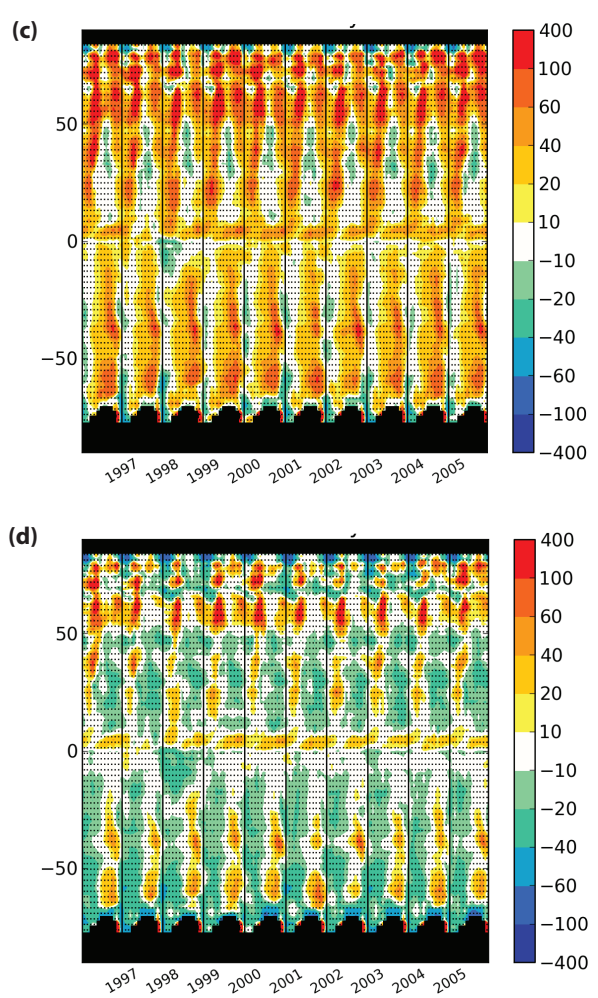

Figure 9. Monthly SST and MLD biases against Reynolds et al. (2002) and de Boyer Montégut et al. (2004) climatology, respectively, in years 1996-2005 as a function of latitude: (a) GO1 SST, (b) GO5.0 SST, (c) GO1 MLD, and (d) GO5.0 (monthly) MLD.
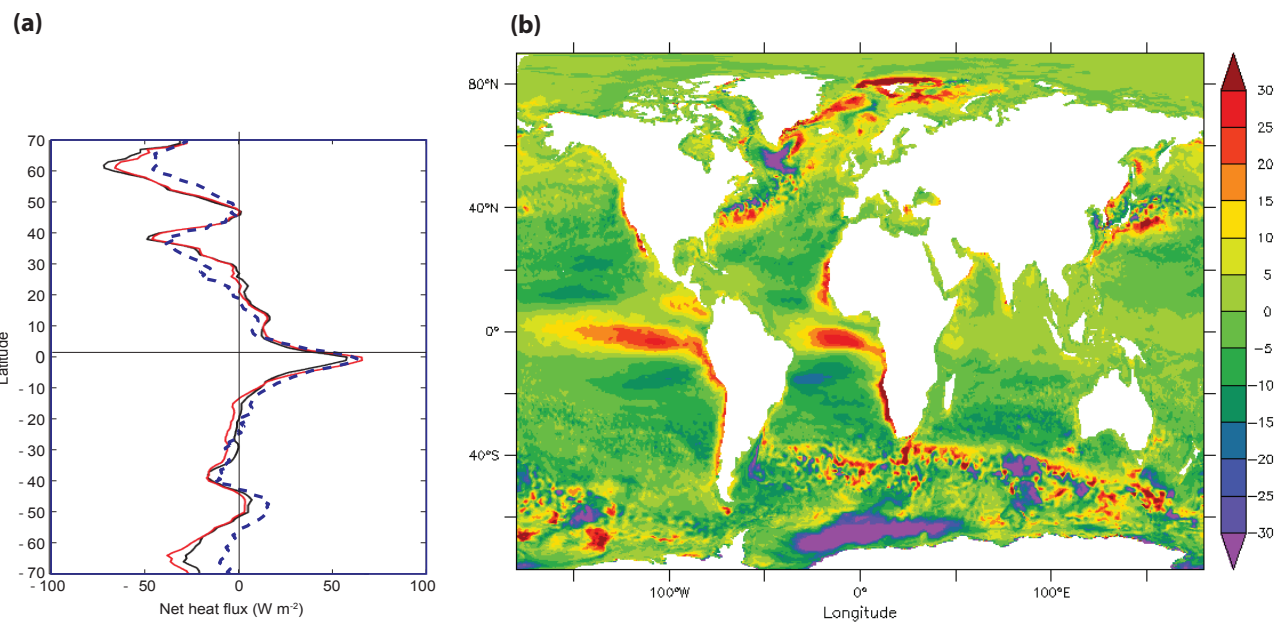

Figure 10. (a) Zonal mean net air-sea heat flux in GO1 (black), GO5.0 (red) and CORE2 data (dashed blue line) in years 1996-2005; and (b) surface net downward heat flux difference GO5.0 minus GO1. This panel is adapted from Fig. 5.10 of Josey et al. (2013).

final 5 years (1981-1985) of each 10-year integration; the main comparison will be of the surface fields, but the global subsurface biases down to $700 \mathrm{~m}$ will also be compared. We use an empirical criterion for the significance of the changes, since the variance of the fields discussed here was not available in the model output: we judge a modification to have a negligible effect if it leads only to differences in the 5-year mean field with the characteristic signature of the mesoscale eddy field, while modifications which lead to coherent largescale changes in temperature or salinity are deemed to have a significant effect. 
(a)

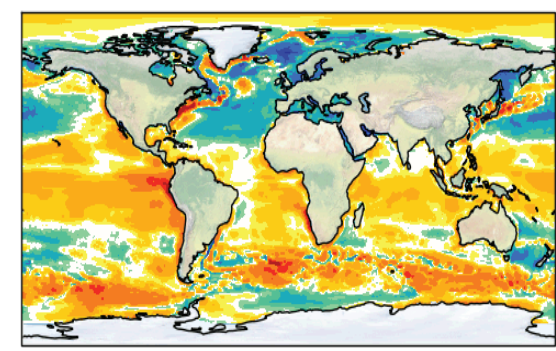

(b)

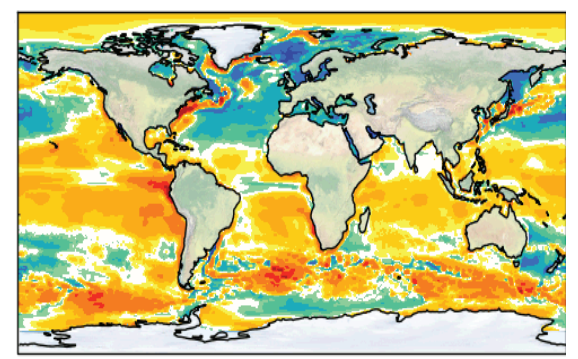

(c)

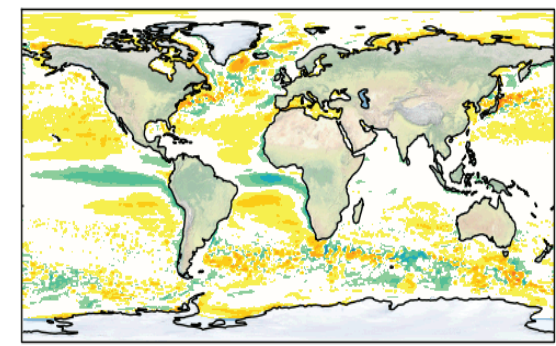

(d)

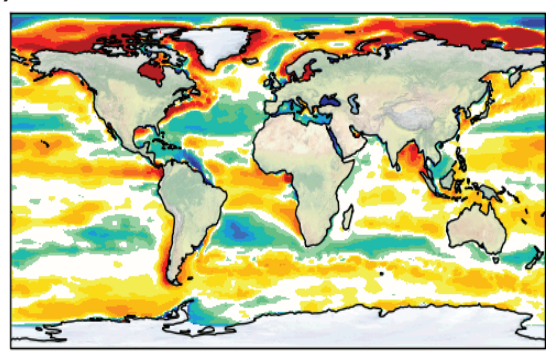

(e)

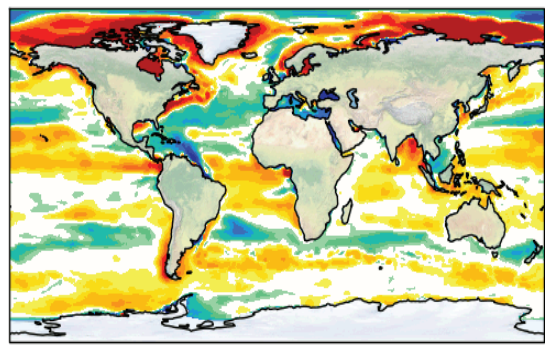

(f)
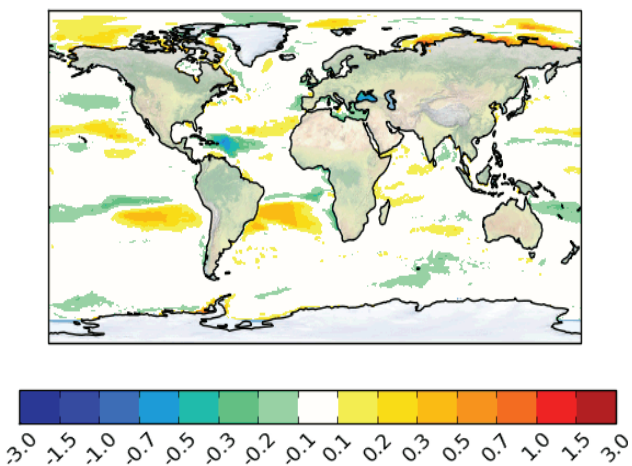

Figure 11. Effect on sea surface fields in years 1981-1985 of ocean code upgrade from v3.2 (GO1) to v3.4 (N3.4): (a) GO1 SST bias, (b) N3.4 SST bias, (c) N3.4 minus GO1 SST, (d) GO1 SSS bias, (e) N3.4 SSS bias, and (f) N3.4 minus GO1 SSS.

\subsubsection{Correction to TKE convective mixing}

The code changes from NEMO versions 3.2-3.4 have one main physics component, which is the correction to the treatment of convective mixing in the TKE scheme described in Sect. 3. As explained in Sect. 3, the expected change to the solution due to this correction is an improvement in the excessively deep wintertime mixing. Figure 11 shows that the code upgrade clearly has significant effects on the surface fields: there are basin-scale changes over almost the whole ocean, with warming of $0.1-0.2^{\circ} \mathrm{C}$ over the Arctic and the subtropical gyres, but cooling by a similar magnitude on the Equator and coastal upwelling regions, in the Southern
Ocean and in the North Atlantic subpolar gyre. The surface salinity changes are also predominantly in zonal bands, with the largest increases of 0.2-0.4 psu between 15 and $30^{\circ} \mathrm{S}$ and between 15 and $30^{\circ} \mathrm{N}$ in the Atlantic and eastern Pacific and a surface freshening over much of the Southern Ocean. The code change overall, however, has little effect on the rms surface errors of the model: the rms SST error decreases from 0.665 to $0.657^{\circ} \mathrm{C}$, while the rms surface salinity error barely changes from 0.828 to $0.825 \mathrm{psu}$. There are, however, major subsurface effects resulting from the code upgrade, particularly from the correction to the treatment of convective mixing in the TKE scheme: comparing the temperature changes in the upper $700 \mathrm{~m}$ with the mean isopycnal depths (Fig. 12) 
(a)

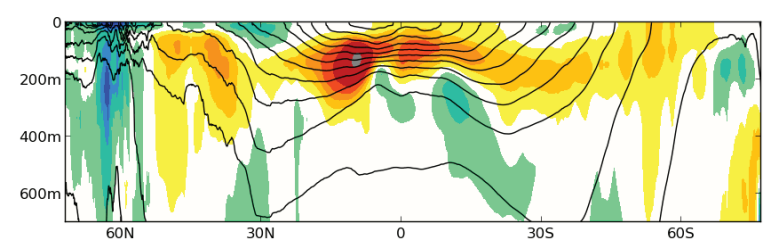

(b)

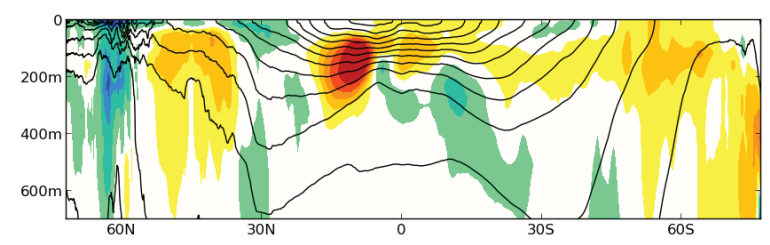

(c)

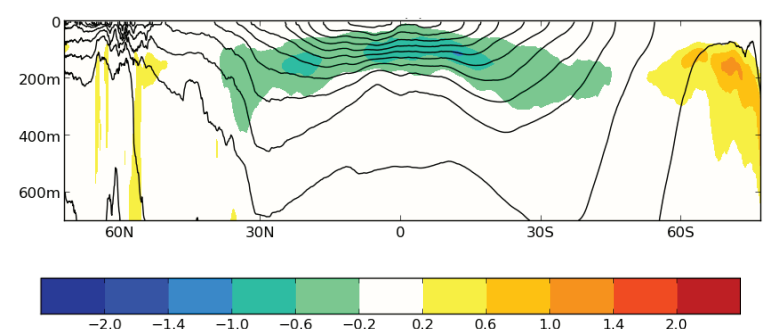

Figure 12. Effect on zonal mean temperature in years 1981-1985 of code upgrade from NEMO v3.2 (GO1) to v3.4 (experiment N3.4) in years 1981-1985. (a) Bias in GO1, (b) bias in N3.4, and (c) difference N3.4 minus GO1. The solid contours are of the zonal mean potential density $\sigma_{0}$ in $\mathrm{N} 3.4$, with a spacing of $0.5 \mathrm{~kg} \mathrm{~m}^{3}$.

shows that the upgrade removes much of the warm bias in the thermocline region between $50^{\circ} \mathrm{S}$ and $60^{\circ} \mathrm{N}$, via a mean cooling of up to $1^{\circ} \mathrm{C}$ in the depth range from 50 to $250 \mathrm{~m}$ over these latitudes. Additionally, the drastic reduction in winter MLD biases between v3.2 and v3.4 observed in Fig. 9 can be directly attributed to the convective mixing correction. The crescent shape of the temperature bias with respect to the observations (and of the difference between v3.2 and v3.4) in Fig. 12 reflects the deepening of the thermocline with increasing latitude.

\subsubsection{TKE parameters}

As a reminder to the reader we note that the main reason for performing this sensitivity test was to investigate the effect of altering the vertical length scale for the TKE source term at $1 / 4^{\circ}$ resolution. In the $1^{\circ}$ resolution experiments of Calvert and Siddorn (2013) reducing this length scale in midlatitudes and increasing it in the tropics significantly alleviated an excessively diffuse midlatitude thermocline, reduced summertime mixed layer depths and significantly reduced near-surface temperature biases at midlatitudes. For consistency with theory, we simultaneously made a small increase in the wind-wave energy coefficient and the minimum permitted surface mixing length (controlled by the parameter $r n \_m x l 0$ ) but these are expected to have a negligible impact.

The changes to the TKE scheme parameters lead to a consistent surface warming of between 0.1 and $0.5^{\circ} \mathrm{C}$ north of $30^{\circ} \mathrm{N}$ and south of $30^{\circ} \mathrm{S}$ (Fig. 13), while there is a small cooling of around $0.05^{\circ} \mathrm{C}$ in the tropics. The pattern of the associated salinity changes is more complex, with freshening of up to $0.2 \mathrm{psu}$ in the Arctic, in the subpolar North Pacific, and to a lesser extent in the tropics and along the path of the ACC; and an increase in salinity in the subtropical zones and, interestingly, in the regions dominated by the Amazon and Congo river plumes. The subtropical surface warming is balanced by a cooling down to $300 \mathrm{~m}$ in these latitudes (Fig. 14), consistent with reduced vertical mixing.

We conclude that changing the vertical length scale for the TKE source term has similar beneficial effects at $1 / 4^{\circ}$ resolution as at $1^{\circ}$ resolution and therefore recommend making this change to the existing scheme.

\subsubsection{Bathymetry and background diffusivity and viscosity}

The rationale for upgrading the bathymetry is that the new bathymetry is based on higher-resolution data (ETOPO1 instead of ETOPO2) and therefore more accurate. Upgrading the bathymetry (not shown) leads to small changes in the temperature and salinity in the Arctic, which overall cools by $0.05^{\circ} \mathrm{C}$ or less and freshen by around $0.05 \mathrm{psu}$ : this is likely to be a consequence of minor modifications to the North Atlantic sill topography. There are southward displacements of the path of the topographically steered ACC, north of the Kerguelen Plateau and north of the Pacific-Antarctic Ridge at $140-150^{\circ} \mathrm{W}$, along with a depression of the surface elevation in the Southern Ocean by $3-5 \mathrm{~cm}$ (not shown), which may be associated with alterations in the path and strength of the northward-flowing Antarctic Bottom Water.

The current consensus within the NEMO community is that background diffusivity and viscosity should be of the order of $1.2 \times 10^{-5} \mathrm{~m}^{2} \mathrm{~s}^{-1}$ and $1.2 \times 10^{-4} \mathrm{~m}^{2} \mathrm{~s}^{-1}$ respectively and since these increases do not degrade the model simulation we argue that these are appropriate values to employ. Increasing the background vertical diffusivity and viscosity parameters ( $r n \_a v t 0$ and $r n \_a v m 0$ respectively) by $20 \%$ (not shown) has a small effect on the surface fields, relative to the other parameter changes. There is a general surface freshening in the Arctic by $0.02-0.04$ psu, and a hint of warming north of the ACC, but elsewhere any signal is small compared with the mesoscale noise. In the upper ocean the explicit representation of mixing processes by the TKE scheme dominates the background term, while it is also likely that over much of the ocean the numerical mixing in the model's advection scheme is at least as large as that associated with the $1.2 \times 10^{-5} \mathrm{~m}^{2} \mathrm{~s}^{-1}$ explicit background diffusivity, as discussed in Griffies et al. (2000) and Lee et al. (2002). 
(a)

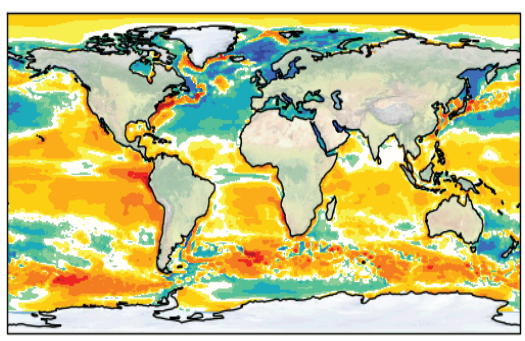

(b)

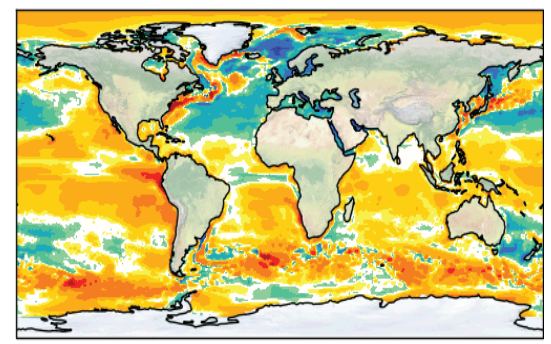

(c)

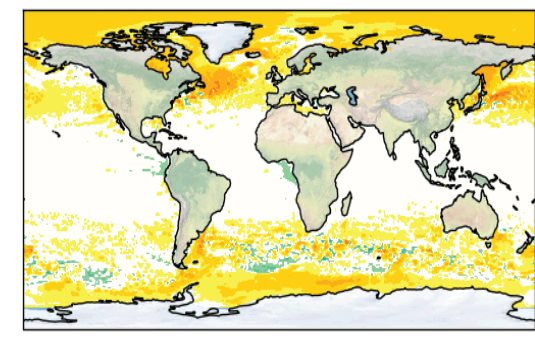

(d)

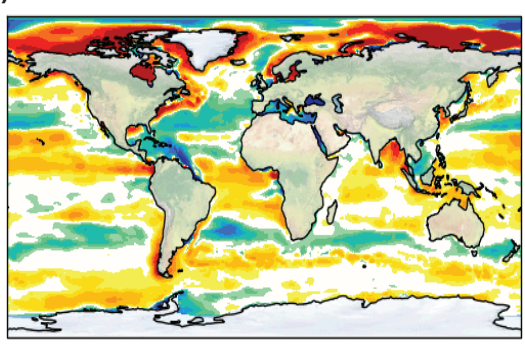

(e)

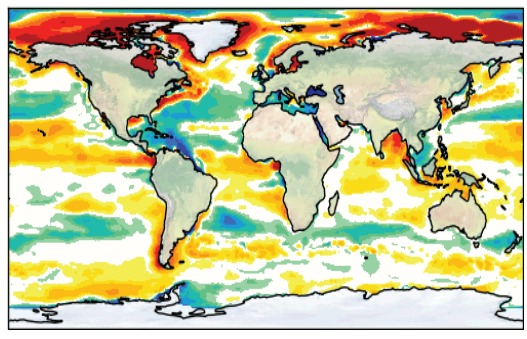

(f)
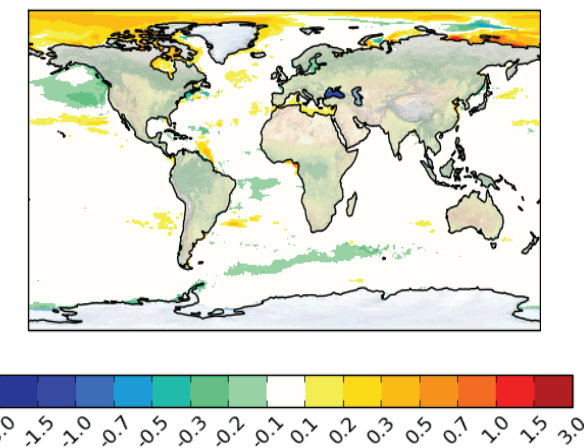

Figure 13. Effect on sea surface fields in years 1981-1985 of TKE scheme changes (from experiment N3.4_vmix to N3.4_tke): (a) N3.4_vmix SST bias, (b) N3.4_tke SST bias, (c) N3.4_tke minus N3.4_vmix SST, (d) N3.4_vmix SSS bias, (e) N3.4_tke SSS bias, and (f) N3.4_tke minus N3.4_vmix SSS.

We conclude that changing the bathymetry and the background vertical mixing parameters does not result in significant global effects on the solution. However we note that the more realistic bathymetry is likely to be important for local circulation, particularly in the Southern Ocean.

\subsubsection{Geothermal heating, double diffusion, bottom boundary layer and ice model changes}

Geothermal heating and double diffusion are physically present in the real ocean, but on the relatively short timescales discussed in this paper, their effects are expected to be small. Nevertheless, in order to make our model as complete as possible, and bearing in mind potential future ap- plications, we explicitly perform sensitivity experiments to evaluate their significance. The addition of benthic geothermal heat input (not shown) leads to a surface freshening of $0.1-0.2$ psu between 40 and $50^{\circ} \mathrm{S}$ in the southwestern Atlantic by the end of the 10-year integration, but little largescale surface effects elsewhere. Adding double diffusion (also not shown) again has relatively little effect on the surface temperature, apart from a small localised cooling along the path of the ACC by $0.05^{\circ} \mathrm{C}$, but does produce a freshening of $0.05 \mathrm{psu}$ over much of the Atlantic and the subtropical Pacific. Neither change was expected to have a large subsurface effect over the timescale discussed here, and this is confirmed by our experiments. 
(a)

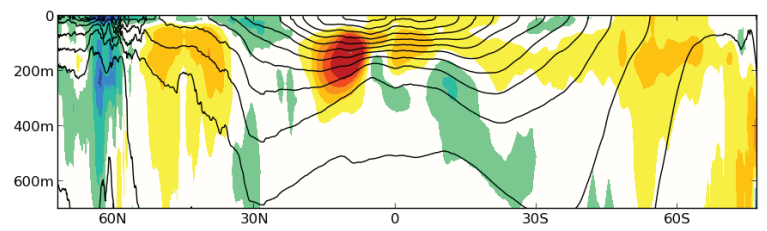

(b)

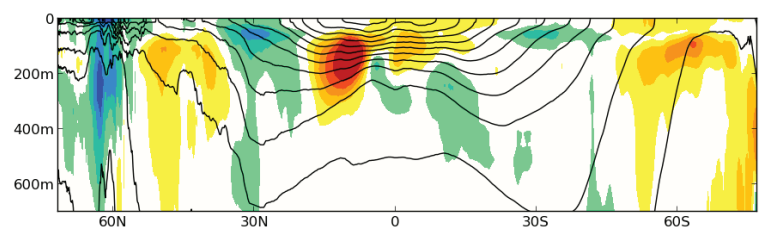

(c)
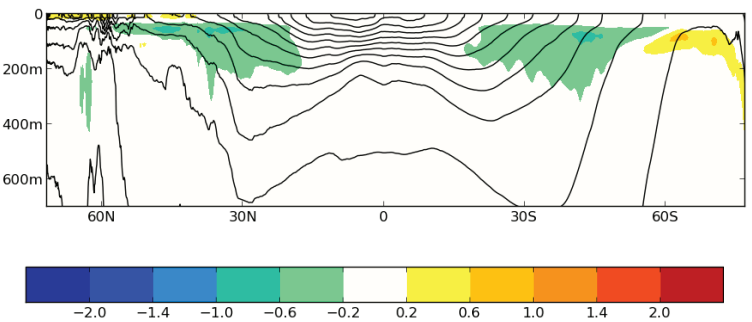

Figure 14. Effect on zonal mean temperature in years 1981-1985 of TKE scheme changes (from experiment N3.4_vmix to N3.4_tke). (a) Bias in N3.4_vmix, (b) bias in N3.4_tke, and (c) difference of N3.4_tke minus N3.4_vmix. The solid contours are of the zonal mean potential density $\sigma_{0}$ in N3.4_tke, with a spacing of $0.5 \mathrm{~kg} \mathrm{~m}^{3}$.

The rationale for inclusion of the bottom boundary layer scheme was to improve the representation of overflows, which are known to be a weak point of $z$-coordinate models such as NEMO. The bottom boundary layer scheme leads to a surface cooling of $\sim 0.2^{\circ} \mathrm{C}$ north of the separated Gulf Stream, while larger modifications of up to $1{ }^{\circ} \mathrm{C}$ to the temperature are seen near the sea floor in the region downstream of the Denmark Strait overflow, but the relationship of the surface signal to the deep temperature signal and associated changes to the deep western boundary current are complex and require further analysis beyond the scope of the present paper.

As explained in Sect. 4, the ice model changes consisted of salinity dependence for the freezing point of water, and increases in the ice's thermal conductivity and salinity, in line with the latest observations. The addition of salinity dependence is justified on the grounds that it is more realistic, whilst the changes to the ice's salinity and thermal conductivity are based on the work of Rae et al. (2014) where the ice model parameters were tuned to reach agreement with the observed seasonal cycle of ice extent. The changes to the ice model (not shown) yield a surface cooling (of $\sim 0.2^{\circ} \mathrm{C}$ ) and freshening (of $\sim 0.1 \mathrm{psu}$ ) in the Southern Ocean and a similar cooling in the Arctic. The change in salinity is consistent with increased salt export from the polar regions (both polar regions are associated with net ice export). The increased thermal conductivity is expected to increase ice formation and overall ice cover and hence to reduce the annual mean surface water temperature (since at a given location there will be a longer ice-covered period annually compared to the previous model configuration, GO1).

\subsubsection{Attribution study summary}

In summary, we find that the largest changes result firstly from the ocean code version upgrade from NEMO v3.2 to v3.4, due to an improvement in handling of diffusion of TKE when convection occurs; and secondly from the changes to the parameters of the TKE scheme; namely, the parameters $r n \_e b b, r n \_m x l 0$, and $n n \_h t a u$. These have only a small effect on the surface errors, but in combination the two changes result in much more substantial improvement of the subsurface temperature field and the seasonal cycle, as described in Sect. 5.2.

\section{Summary and discussion}

We have introduced a new ocean model configuration, GO5.0, developed jointly between the Met Office and NERC. This is an implementation of version 3.4 of the NEMO model, on the ORCA025 grid, with horizontal resolution of at least $1 / 4^{\circ}$ everywhere, together with the CICE sea ice model on the same grid. The GO5.0 model configuration is derived from the previous GO1 through an upgrade of the NEMO code version from version 3.2, and a set of parameter changes. A 30-year integration of GO5.0, run with CORE2 surface forcing from 1976 to 2005, has been compared with GO1 with the same forcing. We have additionally described a set of 10-year sensitivity studies carried out to attribute changes in the model performance to individual changes in the model physics.

The GO5.0 configuration was validated against observations during the final 10 years of the 30 -year integration. It was found to have a generally warm surface bias, with respect to the EN3 climatological data set, of $0.5-1{ }^{\circ} \mathrm{C}$ in the tropics, a cool bias of similar magnitude in the extratropics and a warm bias of around $2{ }^{\circ} \mathrm{C}$ in much of the Southern Ocean. The surface salinity biases were again predominantly zonal, being up to 0.2 psu too salty close to the Equator and in subpolar regions and the Arctic, and too fresh in the subtropics. In the Labrador Sea and in the North Atlantic subpolar gyre the surface waters are between 2 and $4{ }^{\circ} \mathrm{C}$ too warm, and around 1 psu too salty.

Both GO1 and GO5.0 model configurations showed good skill in simulating oceanic exchanges between North Atlantic, North Pacific and Arctic oceans. The net oceanic 
exports from the Arctic Ocean and the contributions from the individual straits are within the uncertainties of the observational estimates. The main model bias is a more vigorous exchange between the Atlantic and Arctic oceans manifesting itself in too strong (compared to observations) a northward flow of the buoyant warm Atlantic water and too strong a return flow of the dense Arctic water as the overflows across the Greenland-Scotland Ridge. The overturning circulation at $26^{\circ} \mathrm{N}$ in the Atlantic was correspondingly stronger than that observed, at $21 \mathrm{~Sv}$. The transport in the Antarctic Circumpolar Current was $124 \mathrm{~Sv}$, close to observed estimates, while the Indonesian Throughflow was significantly higher than observations, most likely because of insufficient mixing at the critical straits.

Comparison of the sea ice in the Northern Hemisphere in GO5.0 and observations show that the model simulates the annual means, the interannual trend and the seasonal cycle well, although the model underestimates summer sea ice extent. In the Southern Hemisphere the sea ice extent again compares well with observations, although the recent rising trend in sea ice cover is not simulated in GO5.0, as is also the case in several other comparable models. Both GO1 and GO5.0 underestimate sea ice volume in the Northern Hemisphere with biases larger in summer than in winter. In the Southern Hemisphere the seasonal cycle of sea ice thickness is simulated correctly, with a moderate underestimation (of $15 \%$ for GO5.0) of the hemisphere-averaged sea ice thickness.

The main differences between GO5.0 and GO1 were seen in the penetration of heat and salt into the interior ocean above the thermocline and in the representation of the seasonal cycle. The global mean warming, with a maximum at $200 \mathrm{~m}$ depth, was reduced from 0.7 to $0.3^{\circ} \mathrm{C}$, while the steady freshening trend at the same depth was also reduced by $10-20 \%$. Although the overall reduction in mixed layer depth from GO1 to GO5.0 did not lead to unequivocal improvements in surface biases, wintertime mixed layers were consistently better represented in GO5.0, while the shallow bias in MLD and consequent warm surface bias in GO1 in tropical latitudes were significantly ameliorated in GO5.0.

To attribute the changes seen between GO1 and GO5.0, the physics modifications were applied incrementally starting from the original GO1 configuration. First of all the NEMO source code was upgraded from v3.2 to v3.4; then the model bathymetry was upgraded; the background vertical diffusivity and viscosity were increased; some of the TKE scheme parameters were adjusted; geothermal heat flux and double diffusion of tracers were added; a scheme was added to represent a bottom boundary layer; and, finally, modifications were made to the ice model. It was found that several of the modifications led to changes with large spatial scales in the model surface and subsurface fields that were distinguishable from the eddy variability, but the dominant effects were traced to the code upgrade and to the TKE changes. These two changes, which both affect mainly vertical mixing in the upper few-hundred metres, were found to produce most of the reduction of the subsurface temperature and salinity biases of the model, along with the reduced errors in the seasonal cycle.

We conclude that GO5.0 represents a significant improvement in realism over the previous configuration of the Met Office ocean model, GO1. In particular, the improvements in the representation of vertical mixing (associated both with the code upgrade from the NEMO v3.2 and in the modifications to the TKE vertical mixing scheme in v3.4) lead to a more faithful simulation of the annual cycle in surface temperature and mixed layer depth, as well as to reduced subsurface drifts in the depth range of $200-400 \mathrm{~m}$.

There are clearly aspects of the GO5.0 configuration that need to be improved further. In particular, the subpolar North Atlantic and the Southern Ocean show substantial errors in both surface and subsurface fields that may be at least partly ascribed to deficiencies in model physics. Process evaluation groups (PEGs) have been set up within the JOMP programme specifically to address issues relating to the two aforementioned regions, and work is ongoing in both cases.

In addition, GO5.0 does not contain several physics upgrades which are currently either available or under development in NEMO, and which offer potentially significant improvements in model realism. These include embedded sea ice (in which the base of the sea ice lies beneath the ocean surface and the ice displaces a non-zero volume of sea water); and the $z$-tilde modification to the vertical coordinate to reduce numerical mixing from high-frequency vertical motions (Leclair and Madec, 2011). The full non-linear free surface physics is available in NEMO v3.4, but not implemented in GO5.0; it is expected that this, along with $z$ tilde and the embedded ice, will be included in future implementations of the global ocean model. 


\section{Appendix A: Code availability and model trunk and branches}

The model code for NEMO v3.4 is available from the NEMO website (www.nemo-ocean.eu). On registering, individuals can access the FORTRAN code using the open source subversion software (http://subversion.apache.org/). The revision number of the base NEMO code (trunk) used for this paper is 3424. In addition we apply some modifications to the base code (branches). Please contact the authors for more information on these branches and how to obtain them.

The model code for CICE is freely available from the United States Los Alamos National Laboratory (http:// oceans11.lanl.gov/trac/CICE/wiki/SourceCode), again using subversion. The revision number for the version used for this paper is 430 (trunk). Once again there are some additional modifications (branches) made for the purposes of this paper, and interested readers are requested to contact the authors for details.

UK users with access to PUMA (cms.ncas.ac.uk/wiki/ PumaService) can copy the job details (job ID xhimo) and submit a duplicate job using the Met Office Unified Model user interface (UMUI).

\section{Appendix B: FPP keys used in GO5.0 (NEMO and CICE)}

key_dynspg_flt - filtered free surface

key_ldfslp - rotate diffusion operators

(for tracer isopycnal diffusion)

key_traldf_c2d - geographically varying lateral tracer diffusion

key_dynldf_c2d - geographically varying lateral momentum diffusion

key_zdftke - TKE scheme for vertical mixing

key_zdftmx - include tidal mixing scheme

key_zdfddm - include double diffusive mixing

parameterisation

key_trabbl - include bottom boundary layer scheme.

\section{Appendix C: Ocean and ice name lists for GO5.0}

These are included as the Supplement.

\section{Appendix D: Surface forcing}

These are the CORE- 2 forcing data set (Large and Yeager, 2009), available at: http://rda.ucar.edu/datasets/ds260.2/.

\section{Appendix E: Other input files}

Other files such as bathymetry, river runoff mask and interpolation weights for the surface forcing are required to run GO5.0. These can be obtained on request from the authors. 


\section{The Supplement related to this article is available online at doi:10.5194/gmd-7-1069-2014-supplement.}

Acknowledgements. The NOC authors were funded by Natural Environment Research Council (UK) National Capability Funding. Met Office authors were supported by the Joint UK DECC/DEFRA Met Office Hadley Centre Climate Programme (GA01101). Funding support from the European Community's Seventh Framework Programme FP7/2007-2013 under grant agreement no. 283367 (MyOcean2) is gratefully acknowledged. We acknowledge use of the MONSooN system, a collaborative facility supplied under the Joint Weather and Climate Research Programme, which is a strategic partnership between the Met Office and the Natural Environment Research Council.The authors would like to thank Adam Blaker for his comments and suggestions, and Andrew Coward and Chris Harris for assistance with setting up and running the simulations. Ship-based Antarctic sea ice thickness data were provided by the SCAR Antarctic Sea Ice Processes and Climate (ASPeCt) program (aspect.antarctica.gov.au).

Edited by: S. Easterbrook

\section{References}

Aagaard, K., Weingartner, T., Danielson, S. L., Woodgate, R. A., Johnson, G. C., and Whitledge, T. E.: Some controls on flow and salinity in Bering Strait, Geophys. Res. Lett., 33, L19602, doi:10.1029/2006GL026612, 2006.

Aksenov, Y., Bacon, S., Coward, A., and Holliday, N. P.: Polar Outflow from the Arctic Ocean: a high resolution model study, J. Marine Syst., 83, 14-37, 2010.

Amante, C. and Eakins, B. W.: ETOPO1 1 Arc-Minute Global Relief Model: Procedures, Data Sources and Analysis, NOAA Technical Memorandum NESDIS NGDC-24, 19 pp., 2009.

Arakawa, A.: Computational design of long-term numerical integration of the equations of fluid motion, J. Comput. Phys., 1, 119-143, 1966.

Arribas, A., Glover, M., Maidens, A., Peterson, K., Gordon, M., MacLachlan, C., Graham, R., Fereday, D., Camp, J., Scaife, A., Xavier, P., McLean, P., Colman, A., and Cusack, S.: The GloSea4 ensemble prediction system for seasonal forecasting, Mon. Weather Rev., 139, 1891-1910, doi:10.1175/2010MWR3615.1, 2011.

Årthun, M., Nicholls, K. W., and Boehme, L.: Wintertime Water Mass Modification near an Antarctic Ice Front, J. Phys. Oceanogr., 43, 359-365, doi:10.1175/JPO-D-12-0186.1, 2013.

Axell, L. B.: Wind-driven Internal Waves and Langmuir Circulations in a Numerical Ocean Model of the Southern Baltic Sea, J. Geophys. Res., 107, 3204, doi:10.1029/2001JC000922, 2002.

Barnier, B., Madec, G., Penduff, T., Molines, J.-M., Treguier, A.M., Le Sommer, J., Beckmann, A., Biastoch, A., Böning, C., Dengg, J., Derval, C., Durand, E., Gulev, S., Remy, E., Talandier, C., Theetten, S., Maltrud, M., McClean, J., and De Cuevas, B.: Impact of partial steps and momentum advection schemes in a global ocean circulation model at eddy permitting resolution,
Ocean Dynam., 56, 543-567, doi:10.1007/s10236-006-0082-1, 2006.

Beckmann, A. and Doscher, R.: A method for improved representation of dense water spreading over topography in geopotentialcoordinate models, J. Phys. Oceanogr., 27, 581-591, 1997.

Bitz, C. M. and Lipscomb, W. H.: An energy-conserving thermodynamic model of sea ice, J. Geophys. Res., 104, 15669-15677, 1999.

Bitz, C. M., Holland, M., Eby, M., and Weaver, A. J.: Simulating the ice-thickness distribution in a coupled climate model, J. Geophys. Res., 106, 2441-2463, 2001.

Blaker, A. T., Hirschi, J. J.-M., McCarthy, G., Sinha, B., Taws, S., Marsh, R., Coward, A. C., and de Cuevas, B. A.: Historical analogues of the recent extreme minima observed in the Atlantic meridional overturning circulation at $26^{\circ} \mathrm{N}$, Clim. Dynam., in review, 2014.

Bourdalle-Badie, R. and Treguier, A.-M.: A climatology of runoff for the global ocean-ice model ORCA025, Report, MercatorOcean, MOO-RP-425-365-MER, 2006.

Brown, A., Milton, S., Cullen, M., Golding, B., Mitchell, J., and Shelley, A.: Unified modeling and prediction of weather and climate: a 25-year journey, B. Am. Meteorol. Soc., 93, 1865-1877, 2012.

Calvert, D. and Siddorn, J.: Revised vertical mixing parameters for the UK community standard configuration of the global NEMO ocean model, Hadley Centre Technical Note 95, 74 pp., available at: http://www.metoffice.gov.uk/media/pdf/9/0/HCTN_ 95.pdf, last access: 21 May 2014, 2013.

Cavalieri, D. J., Parkinson, C. L., Gloersen, P., and Zwally, H.: Sea ice concentrations from Nimbus-7 SMMR and DMSP SSM/ISSMIS passive microwave data, [indicate subset used], NASA DAAC at the National Snow and Ice Data Center, Boulder, Colorado, USA, 1996 (updated yearly).

Clement Kinney, J., Maslowski, W., Aksenov, Y., de Cuevas, B., Nguyen, A., Osinski, R., Steele, M., Woodgate, R. A., and Zhang, J.: On the Flow Through Bering Strait: A Synthesis of Model Results and Observations, in: The Pacific Arctic Region. Ecosystem Status and Trends in a Rapidly Changing Environment, edited by: Grebmeier, J. M. and Maslowski, W., Springer, 2014.

Collins, W. J., Bellouin, N., Doutriaux-Boucher, M., Gedney, N., Hinton, T., Jones, C. D., Liddicoat, S., Martin, G., O'Connor, F., Rae, J., Senior, C., Totterdell, I., Woodward, S., Reichler, T., and Kim, J.: Evaluation of the HadGEM2 model, Met Office Hadley Centre Technical Note no. HCTN 74, available from Met Office, FitzRoy Road, Exeter EX1 3PB, available at: http://www.metoffice.gov.uk/media/pdf/8/7/HCTN_74. pdf, last access: 18 November 2013, 2008.

Craig, P. D. and Banner, M. L.: Modelling Wave-Enhanced Turbulence in the Ocean Surface Layer, J. Phys. Oceanogr., 24, 25462559, 1994.

Cunningham, S. A., Alderson, S. G., King, B. A., and Brandon, M. A.: Transport and variability of the Antarctic Circumpolar Current in Drake Passage, J. Geophys. Res., 108, 8084, doi:10.1029/2001JC001147, 2003.

Cuny, J., Rhines, P., and Kwok, R. R.: Davis Strait volume, freshwater and heat fluxes, Deep-Sea Res. Pt. I, 52, 519-542, 2005.

Curry, B., Lee, C. M., and Petrie, B.: Volume, freshwater, and heat fluxes through Davis Strait, 2004-2005, J. Phys. Oceanogr., 41, 429-462, doi:10.1175/2010JPO4536.1, 2011. 
Dai, A. and Trenberth, K. E.: Estimates of freshwater discharge from continents: latitudinal and seasonal variations, J. Hydrometeorol., 3, 660-687, 2002.

Danabasoglu, G., Large, G. W., and Briegleb, B.: Climate impacts of parameterized Nordic Sea overflows, J. Geophys. Res., 115, C11005, doi:10.1029/2010JC006243, 2010.

Dawson, A., Matthews, A. J., Stevens, D. P., Roberts, M. J., and Vidale, P.-L.: Importance of oceanic resolution and mean state on the extra-tropical response to El Nino in a matrix of coupled models, Clim. Dynam., 41, 1439-1452, doi:10.1007/s00382012-1518-6, 2012.

de Boyer Montégut, C., Madec, G., Fischer, A. S., Lazar, A., and Iudicone, D.: Mixed layer depth over the global ocean: an examination of profile data and a profile-based climatology, J. Geophys. Res., 109, C12003, doi:10.1029/2004JC002378, 2004.

Delworth, T., Rosati, A., Anderson, W., Adcroft, A., Balaji, V., Benson, R., Dixon, K., Griffies, S., Lee, H., Pacanowski, R., Vecchi, G. A., Wittenberg, A. T., Zeng, F., and Zhang, R.: Simulated climate and climate change in the GFDL CM2.5 high-resolution coupled climate model, J. Climate, 25, 2755-2781, 2012.

Farneti, R. and Gent, P. R.: The effects of the eddy-induced advection coefficient in a coarse-resolution coupled climate model, Ocean Model., 39, 135-145, doi:10.1016/j.ocemod.2011.02.005, 2011.

Farneti, R., Delworth, T. L., Rosati, A. J., Griffies, S. M., and Zeng, F.: The role of mesoscale eddies in the rectification of the Southern Ocean response to climate change, J. Phys. Oceanogr., 40, 1539-1557, doi:10.1175/2010JPO4353.1, 2010.

Gammelsrod, T., Leikvin, O., Lien, V., Budgell, W. P., Loeng, H., and Maslowski, W.: Mass and heat transports in the NE Barents Sea: observations and models, J. Marine Syst., 75, 56-69, doi:10.1016/j.jmarsys.2008.07.010, 2009.

Gaspar, P., Grégoris, Y., and Lefevre, J.-M.: A simple eddy kinetic energy model for simulations of the oceanic vertical mixing: tests at Station Papa and long-term upper ocean study site, J. Geophys. Res., 95, 16179-16193, doi:10.1029/JC095iC09p16179, 1990.

Gent, P. R. and Danabasoglu, G.: Response to Increasing Southern Hemisphere Winds in CCSM4, J. Climate, 24, 4992-4998, doi:10.1175/JCLI-D-10-05011.1, 2011.

Gent, P. R. and McWilliams, J. C.: Isopycnal mixing in ocean circulation models, J. Phys. Oceanogr., 20, 150-155, 1990.

Gnanadesikan, A., Griffies, S. M., and Samuels, B. L.: Effects in a climate model of slope tapering in neutral physics schemes, Ocean Model., 16, 1-16, 2007.

Gordon, C., Cooper, C., Senior, C. A., Banks, H., Gregory, J. M., Johns, T. C., Mitchell, J. F. B., and Wood, R. A.: The simulation of SST, sea ice extents and ocean heat transports in a version of the Hadley Centre coupled model without flux adjustments, Clim. Dynam., 16, 147-168, 2000.

Gregg, M. C., Sanford, T. B., and Winkel, D. P.: Reduced mixing from the breaking of internal waves in equatorial waters, Nature, 422, 513-515, 2003.

Griffies, S. M., Pacanowski, R. C., and Hallberg, R. W.: Spurious diapycnal mixing associated with advection in a $\mathrm{z}$-coordinate ocean model, Mon. Weather Rev., 128, 538-564, 2000.

Griffies, S. M., Biastoch, A., Böning, C., Bryan, F., Danabasoglu, G., Chassignet, E. P., England, M. H., Gerdes, R., Haak, H., Hallberg, R. W., Hazeleger, W., Jungclaus, J., Large, W. G., Madec, G., Pirani, A., Samuels, B. L., Scheinert, M., Sen
Gupta, A., Severijns, C. A., Simmons, H. L., Treguier, A.M., Winton, M., Yeager, S., and Yin, J.: Coordinated Oceanice Reference Experiments (COREs), J. Ocean Model., 26, doi:10.1016/j.ocemod.2008.08.007, 2009.

Hallberg, R. and Gnanadesikan, A.: The role of eddies in determining the structure and response of the wind-driven Southern Hemisphere overturning: results from the Modeling Eddies in the Southern Ocean (MESO) project, J. Phys. Oceanogr., 36, 2232 2252, 2006.

Hewitt, H. T., Copsey, D., Culverwell, I. D., Harris, C. M., Hill, R. S. R., Keen, A. B., McLaren, A. J., and Hunke, E. C.: Design and implementation of the infrastructure of HadGEM3: the nextgeneration Met Office climate modelling system, Geosci. Model Dev., 4, 223-253, doi:10.5194/gmd-4-223-2011, 2011.

Hirschi, J. J.-M., Blaker, A. T., Sinha, B., Coward, A., de Cuevas, B., Alderson, S., and Madec, G.: Chaotic variability of the meridional overturning circulation on subannual to interannual timescales, Ocean Sci., 9, 805-823, doi:10.5194/os-9-805-2013, 2013.

Holland, P. R. and Kwok, R.: Wind-driven trends in Antarctic seaice drift, Nat. Geosci., 5, 872-875, doi:10.1038/ngeo1627, 2012.

Houghton, J. T., Ding, Y., Griggs, D. J., Noguer, M., van der Linden, P. J., and Xiaosu, D.: Climate Change 2001: The Scientific Basis, Cambridge University Press, 944 pp., 2001.

Hunke, E. C. and Dukowicz, J. K.: An Elastic-Viscous-Plastic Model for sea ice dynamics, J. Phys. Oceanogr., 27, 1849-1867, 1997.

Hunke, E. C. and Lipscomb, W. H.: CICE: The Los Alamos Sea Ice Model, Documentation and Software User's Manual, Version 4.1, Tech. Rep. LA-CC-06-012, Los Alamos National Laboratory, Los Alamos, New Mexico, available at: http://oceans11. lanl.gov/trac/CICE, last access: 18 November 2013, 2010.

Ingleby, B. and Huddleston, M.: Quality control of ocean temperature and salinity profiles - historical and real-time data, J. Marine Syst., 65, 158-175, 2007.

IOC, IHO and BODC: Centenary Edition of the GEBCO Digital Atlas, published on CD-ROM on behalf of the Intergovernmental Oceanographic Commission and the International Hydrographic Organization as part of the General Bathymetric Chart of the Oceans, British Oceanographic Data Centre, Liverpool, UK, 2003.

Johns, T. C., Durman, C. F., Banks, H. T., Roberts, M. J., McLaren, A. J., Ridley, J. K., Senior, C. A., Williams, K. D., Jones, A., Rickard, G. J., Cusack, S., Ingram, W. J., Crucifix, M., Sexton, D. M. H., Joshi, M. M., Dong, B.-W., Spencer, H., Hill, R. S. R., Gregory, J. M., Keen, A. B., Pardaens, A. K., Lowe, J. A., BodasSalcedo, A., Stark, S., and Searl, Y.: The New Hadley Centre Climate Model (HadGEM1): evaluation of coupled simulations, J. Climate, 19, 1327-1353, 2006.

Josey, S. A., Gulev, S., and Yu, L.: Exchanges through the ocean surface, in: Ocean Circulation and Climate: A 21st Century Perspective, 2nd Edn., edited by: Siedler, G., Griffies, S., Gould, J., and Church, J., Oxford, GB, Academic Press, International Geophysics Series, 103, 115-140, 2013.

Kennedy, J. J., Rayner, N. A., Smith, R. O., Saunby, M., and Parker, D. E.: Reassessing biases and other uncertainties in sea-surface temperature observations measured in situ since 1850 - Part 2: Biases and homogenisation, J. Geophys. Res., 116, D14104, doi:10.1029/2010JD015220, 2011. 
Koch-Larrouy, A., Madec, G., Blanke, B., and Molcard, R.: Water mass transformation along the Indonesian throughflow in an OGCM, Ocean Dynam., 58, 289-309, 2008.

Large, W. G. and Yeager, S. G.: The global climatology of an interannually varying air-sea flux data set, Clim. Dynam., 33, 341364, doi:10.1007/s00382- 008-0441-3, 2009.

Leclair, M. and Madec, G.: z̃-Coordinate, an Arbitrary LagrangianEulerian coordinate separating high and low frequency motions, Ocean Model., 37, 139-152, doi:10.1016/j.ocemod.2011.02.001, 2011.

Lee, M.-M., Coward, A. C., and Nurser, A. J. G.: Spurious diapycnal mixing of the deep waters in an eddy-permitting global ocean model, J. Phys. Oceanogr., 32, 1522-1535, 2002.

Lohmann, G., Gerdes, R., and Chen, D.: Sensitivity of the thermohaline circulation in coupled oceanic GCM-atmospheric EBM experiments, Clim. Dynam., 12, 403-416, 1996.

Madec, G.: NEMO - the OPA9 ocean engine: Note du Pole de Modelisation, Institut Pierre-Simion Laplace, 1:100, available at: http://www.nemo-ocean.eu, last access: 18 November 2013, 2008.

McCarthy, G., Frajka-Williams, E., Johns, W. E., Baringer, M. O., Meinen, C. S., Bryden, H. L., Rayner, D., Duchez, A., Roberts, C., and Cunningham, S. A.: Observed interannual variability of the Atlantic meridional overturning circulation at $26.5^{\circ} \mathrm{N}$, Geophys. Res. Lett., 39, L19609, doi:10.1029/2012GL052933, 2012.

Megann, A. P., New, A. L., Blaker, A. T., and Sinha, B.: The sensitivity of a coupled climate model to its ocean component, J. Climate, 23, 5126-5150, 2010.

Meijers, A. J. S., Shuckburgh, E., Bruneau, N., Sallee, J.-B., Bracegirdle, T. J., and Wang, Z.: Representation of the Antarctic Circumpolar Current in the CMIP5 climate models and future changes under warming scenarios, J. Geophys. Res., 117, C12008, doi:10.1029/2012JC008412, 2012.

Merryfield, W. J., Holloway, G., and Gargett, A. E.: A global ocean model with double-diffusive mixing, J. Phys. Ocean., 29, 11241142, 1999.

Munday, D. R., Johnson, H. L., and Marshall, D. P.: Eddy Saturation of Equilibrated Circumpolar Currents, J. Phys. Ocean., 43, $507-$ 532, doi:10.1175/JPO-D-12-095.1, 2013.

Olsen, S. M., Hansen, B., Quadfasel, D., and Østerhus, S.: Observed and modelled stability of overflow across the GreenlandScotland ridge, Nature, 455, 519-522, 2008.

Østerhus, S., Turrrell, W. R., Jónsson, S., and Hansen, B.: Measured volume, heat, and salt fluxes from the Atlantic to the Arctic Mediterranean, Geophys. Res. Lett., 32, L07603, doi:10.1029/2004GL022188, 2005.

Penduff, T., Le Sommer, J., Barnier, B., Treguier, A.-M., Molines, J.-M., and Madec, G.: Influence of numerical schemes on current-topography interactions in $1 / 4^{\circ}$ global ocean simulations, Ocean Sci., 3, 509-524, doi:10.5194/os-3-509-2007, 2007.

Penduff, T., Juza, M., Brodeau, L., Smith, G. C., Barnier, B., Molines, J.-M., Treguier, A.-M., and Madec, G.: Impact of global ocean model resolution on sea-level variability with emphasis on interannual time scales, Ocean Sci., 6, 269-284, doi:10.5194/os6-269-2010, 2010.

Rae, J. G. L., Hewitt, H. T., Keen, A. B., Ridley, J. K., Harris, C. M., Hunke, E. C., and Walters, D. N.: Development of Global Sea Ice 5.0 CICE configuration, Geosci. Model Dev., in preparation, 2014.
Rahmstorf, S. and Willebrand, J.: The role of temperature feedback in stabilizing the thermohaline circulation, J. Phys. Oceanogr., 25, 787-805, doi:10.1175/15200485(1995)025<0787:TROTFI>2.0.CO;2, 1995.

Rayner, N. A., Parker, D. E., Horton, E. B., Folland, C. K., Alexander, L. V., Rowell, D. P., Kent, E. C., and Kaplan, A.: Global analyses of sea surface temperature, sea ice, and night marine air temperature since the late nineteenth century, J. Geophys. Res., 108, 4407, doi:10.1029/2002JD002670, 2003.

Remy, E., Siefridt, L., Fleury, L., and Bremond, M.: Construction de la bathymetrie pour la configuration modele ORCA025, CERFACS Report, May 2003.

Reynolds, R. W., Rayner, N. A., Smith, T. M., Stokes, D. C., and Wang, W.: An improved in situ and satellite SST analysis for climate, J. Climate, 15, 1609-1625, 2002.

Roberts, C. D., Waters, J., Peterson, K. A., Palmer, M. D., McCarthy, G. D., Frajka-Williams, E., Haines, K., Lea, D. J., Martin, M. J., Storkey, D., Blockley, E. W., and Zuo, H.: Atmosphere drives recent interannual variability of the Atlantic meridional overturning circulation at $26.5^{\circ} \mathrm{N}$, Geophys. Res. Lett., 40, 5164-5170, doi:10.1002/grl.50930, 2013.

Roberts, M. J., Clayton, A., Demory, M.-E., Donners, J., Vidale, P.L., Norton, W., Shaffrey, L., Stevens, D. P., Stevens, I., Wood, R. A., and Slingo, J.: Impact of resolution on the tropical pacific circulation in a matrix of coupled models, J. Climate, 22, 25412556, 2009.

Robson, J., Hodson, D., Hawkins, E., and Sutton, R.: Atlantic overturning in decline?, Nat. Geosci., 7, 2-3, 2014.

Saunders, P. P., Cunningham, S. A., de Cuevas, B. A., and Coward, A. C.: Comments on "Decadal Changes in the North Atlantic and Pacific Meridional Overturning Circulation and Heat Flux", J. Phys. Ocean., 38, 2104-2107, 2008.

Scaife, A. A., Copsey, D., Gordon, C., Harris, C., Hinton, T., Keeley, S., O’Neill, A., Roberts, M., and Williams, K.: Improved Atlantic winter blocking in a climate model, Geophys. Res. Lett., 38, L23703, doi:10.1029/2011GL049573, 2011.

Semtner, A. J.: A model for the thermodynamic growth of sea ice in numerical investigations of climate, J. Phys. Oceanogr., 6, 379389, 1976.

Shaffrey, L. C., Stevens, I., Norton, W. A., Roberts, M. J., Vidale, P. L., Harle, J. D., Jarrar, A., Stevens, D. P., Woodage, M. J., Demory, M. E., Donners, J., Clark, D. B., Clayton, A., Cole, J. W., Wilson, S. S., Connolley, W. M., Davies, T. M., Iwi, A. M., Johns, T. C., King, J. C., New, A. L., Slingo, J. M., Slingo, A., Steenman-Clark, L., and Martin, G. M.: U.K. HiGEM: The new U.K. high-resolution global environment model - model description and basic evaluation, J. Climate, 22, 1861-1896, 2009.

Simmons, H., Jayne, S., Laurent, L. S., and Weaver, A.: Tidally driven mixing in a numerical model of the ocean general circulation, Ocean Model., 6, 245-263, 2004.

Sinha, B., Topliss, B., Blaker, A. T., and Hirschi J. J.-M.: A numerical model study of the effects of interannual timescale wave propagation on the predictability of the Atlantic meridional overturning circulation, J. Geophys. Res., 118, 131-146, doi:10.1029/2012JC008334, 2013.

Sirevaag, A., McPhee, M. G., Morison, J. H., Shaw, W. J., and Stanton, T. P.: Wintertime mixed layer measurements at Maud Rise, Weddell Sea, J. Geophys. Res., 115, C02009, doi:10.1029/2008JC005141, 2010. 
Skagseth, Ø., Furevik, T., Ingvaldsen, R., Loeng, H., Mork, K. A., Orvik, K. A., and Ozhigin, V.: Volume and heat transports to the Arctic Ocean via the Norwegian and Barents Seas, in: ArcticSubarctic Ocean Fluxes: Defining the Role of the Northern Seas in Climate, edited by: Dickson, R. R., Meincke, J., and Rhines, P., Springer, the Netherlands, 45-64, 2008.

Smeed, D. A., McCarthy, G. D., Cunningham, S. A., FrajkaWilliams, E., Rayner, D., Johns, W. E., Meinen, C. S., Baringer, M. O., Moat, B. I., Duchez, A., and Bryden, H. L.: Observed decline of the Atlantic meridional overturning circulation 20042012, Ocean Sci., 10, 29-38, doi:10.5194/os-10-29-2014, 2014.

Smith, D. M., Cusack, S., Colman, A. W., Folland, C. K., Harris, G. R., and Murphy, J. M.: Improved surface temperature prediction for the coming decade from a global climate model, Science, 317, 796-799, doi:10.1126/science.1139540, 2007.

Solomon, S., Qin, D., Manning, M., Chen, Z., Marquis, M., Averyt, K. B., Tignor, M., and Miller, H. L.: Climate Change 2007: The Physical Science Basis, Cambridge University Press, 996 pp., 2007.

Sprintall, J., Wijffels, S. E., Molcard, R., and Jaya, I.: Direct estimates of the Indonesian Throughflow entering the Indian Ocean: 2004-2006, J. Geophys. Res., 114, C07001, doi:10.1029/2008JC005257, 2009.

Stein, C. A. and Stein, S.: A model for the global variation in oceanic depth and heat flow with lithospheric age, Nature, 359, 123-129, 1992.

Storkey, D., Blockley, E. W., Furner, R., Guiavarc'h, C., Lea, D., Martin, M. J., Barciela, R. M., Hines, A., Hyder, P., and Siddorn, J. R.: Forecasting the ocean state using NEMO: the new FOAM system, Journal of Operational Oceanography, 3, 3-15, 2010.
Tansley, C. E. and Marshall, D. P.: On the dynamics of wind-driven circumpolar currents, J. Phys. Oceanogr., 31, 3258-3273, 2001.

Thomas, M. D. and Zhai, X.: Eddy-induced variability of the meridional overturning circulation in a model of the North Atlantic, Geophys. Res. Lett., 40, 1-6, doi:10.1002/grl.50532, 2013.

Viebahn, J. and Eden, C.: Towards the impact of eddies on the response of the southern ocean to climate change, Ocean Model., 34, 150-165, 2010.

Williamson, D., Goldstein, M., Allison, L., Blaker, A., Challenor, P., and Jackson, L.: History matching for the quantification and reduction of parametric uncertainty in climate model projections, Clim. Dynam., 41, 1703-1729, doi:10.1007/s00382-013-1896-4, 2013.

Woodgate, R. A., Weingartner, T. J., and Lindsay, R.: Observed increases in Bering Strait oceanic fluxes from the Pacific to the Arctic from 2001 to 2011 and their impacts on the Arctic Ocean water column, Geophys. Res. Lett., 39, L24603, doi:10.1029/2012GL054092, 2012.

Worby, A. P., Geiger, C. A., Paget, M. J., van Woert, M. L., Ackley, S. F., and DeLiberty, T. L.: Thickness distribution of Antarctic sea ice, J. Geophys. Res., 113, C05S92, doi:10.1029/2007JC004254, 2008.

Yeager, S. G. and Jochum, M.: The connection between Labrador Sea buoyancy loss, deep western boundary current strength, and Gulf Stream path in an ocean circulation model, Ocean Model., 30, 207-224, 2009.

Zalesak, S. T.: Fully multidimensional flux corrected transport algorithms for fluids, J. Comput. Phys., 31, 335-362, 1979.

Zhang, J., Thomas, D. R., Rothrock, D. A., Lindsay, R. W., Yu, Y., and Kwok, R.: Assimilation of ice motion observations and comparisons with submarine ice thickness data, J. Geophys. Res., 108, 3170, doi:10.1029/2001JC001041, 2003. 